\title{
OCORRÊNCIA DE AFLATOXINAS, ZEARALENONA E OCRATOXINA A, NO MILHO, A SER UTILIZADO COMO MATÉRIA-PRIMA EM INDÚSTRIA ALIMENTÍCIA DO ESTADO DE SÃO PAULO.
}

\section{EDUARDO MICOTTI DA GLORIA}

(Engenheiro Agrônomo)

Orientador: Prof. Dr. HOMERO FONSECA

Dissertação apresentada à Escola Superior de Agricultura "Luiz de Queiroz", da Universidade de São Paulo, para obtenção do título de Mestre em Ciências.

Área de Concentração: Ciência e Tecnologia de Alimentos.

PIRACICABA

Estado de São Paulo - Brasil

Março - 1995 


\section{OCORRÊNCIA DE AFLATOXINAS, ZEARALENONA E OCRATOXINA A, NO MILHO, A SER UTILIZADO COMO MATÉRIA-PRIMA EM INDƯSTRIA ALIMENTICCIA DO ESTADO DE SÃO PAULO.}

\section{EDUARDO MICOTTI DA GLORIA}

Aprovada em 17.02.1995

Comissão Julgadora

Prof. Dr. Homero Fonseca

ESALQ/USP

Prof. Dr. Cláudio Rosa Gallo

ESALQ/USP

Prof. Dr. Benedito Corrêa

ICB/USP

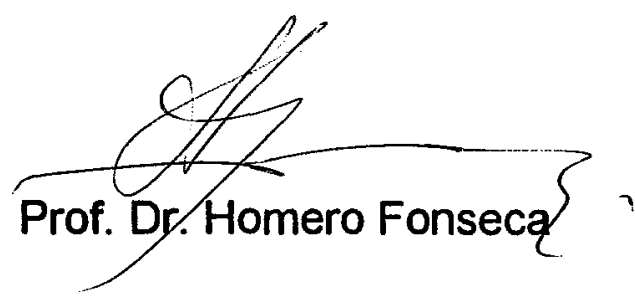




\section{DEDICO}

Aos meus pais, Nadir e Enid Pela compreensão durante todos estes anos;

Aos meus irmãos André, Ronaldo, Mariana e Fábio Pela amizade entre nós;

E a mim

Por mais esta conquista na vida. 


\section{AGRADECIMENTOS}

- Ao Prof. Homero Fonseca pela orientação, sugestões e oportunidade de desenvolver este estudo.

- À companheira Eng. Agron. Maria Antônia Calori-Domingues pela amizade e pelas sugestões sempre valiosas.

- À Biomédica Ivani Valarini Zambello e a Bióloga Ana Helena Stefanovitz pela amizade e auxílio.

- Ao acadêmico Ilman Martins de Souza pelo auxílio fundamental nas atividades deste projeto de pesquisa.

- À Fundação de Amparo à Pesquisa do Estado de São Paulo pelo auxílio financeiro indespensável à realização desta pesquisa.

- À indústria Refinações de Milho Brasil, unidade de Mogi Guaçu, na pessoa do Sr. César Benatti, pelo auxílio e colaboração, na coletada das amostras.

- À bibliotecaria Beatriz Helena de Giongo pelo auxílio na revisão das citações bibliográficas.

- À Escola Superior de Agricultura "Luiz de Queiroz" da Universidade de São Paulo por me proporcionar a utilização da infraestrura básica para 0 desenvolvimento deste projeto.

- E a todas as pessoas que me incentivaram ou de algum modo contribuiram para execução deste projeto de pesquisa. 


\section{SUMÁRIO}

LISTA DE FIGURAS................................................................................ V

LISTA DE TABELAS................................................................................... VI

RESUMO

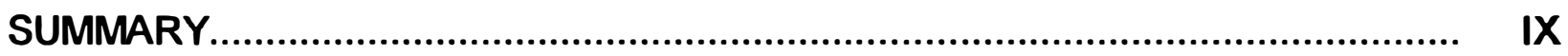

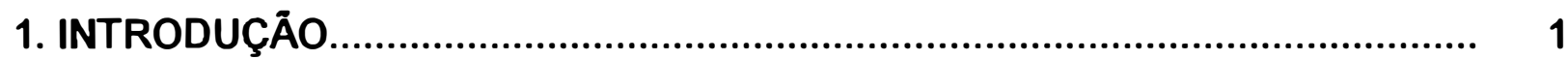

2. OBJETIVOS

3. REVISÃO DE LITERATURA .................................................................... 5

3.1. Aflatoxinas........................................................................................ 5

3.1.1. Características e efeitos tóxicos................................................... 5

3.1.2. Ocorrência.............................................................................. 11

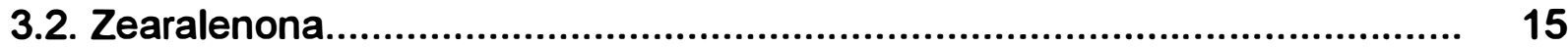

3.2.1. Características e efeitos tóxicos................................................ 15

3.2.2. Ocorrência............................................................................... 18

3.3. Ocratoxina A ................................................................................ 21

3.3.1. Características e efeitos tóxicos................................................. 21

3.3.2. Ocorrência................................................................................. 24

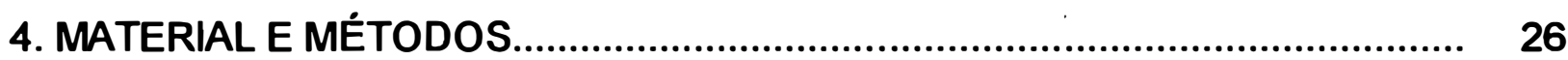

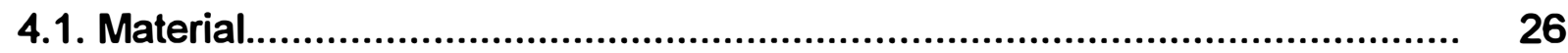

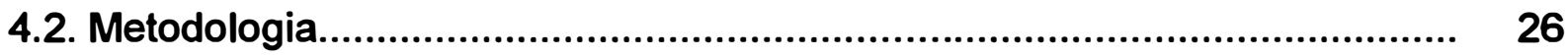

4.2.1. Método de amostragem........................................................... 26

4.2.2. Preparo das amostras............................................................ 27

4.2.3. Metodologia analítica.............................................................. 28

4.2.3.1. Placas cromatográficas, padröes e sistema de solventes.... 28

4.2.3.2. Extração e clarificação da amostra..................................... 29

4.2.3.3. Triagem................................................................... $\quad 30$

4.2.3.4. Quantificação............................................................... 32

4.2.3.5. Confirmação.................................................................... 33

5. RESULTADOS E DISCUSSẢO_.................................................................. 35

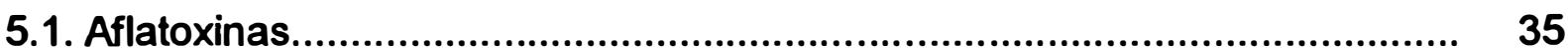

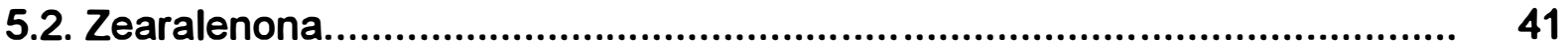

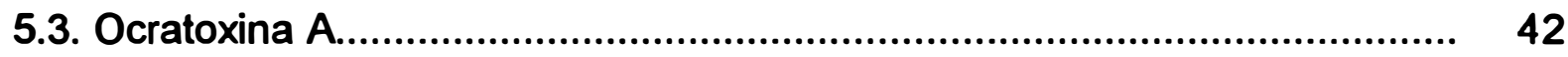




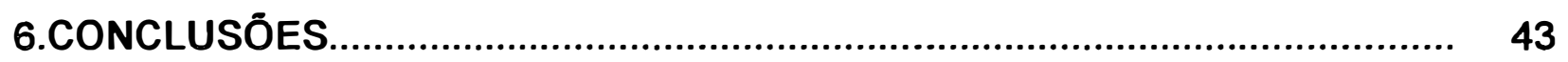

7. REFERÊNCIAS BIBLIOGRÁFICAS......................................................... 59 


\section{LISTA DE FIGURAS}

Figura

Página

1 Esquema de divisão da placa cromatográfica e disposição das alíquotas do padrão e extrato de amostras.

2 Origem do milho por Estado e distribuição da contaminação 


\section{LISTA DE TABELAS}

Tabela

Página

1 Procedência, umidade de entrada na indústria e resultados da contaminação com micotoxinas das 96 amostras coletadas em outubro de 1993.

2 Procedência, umidade de entrada na indústria e resultados da contaminação com micotoxinas das 106 amostras coletadas em março de 1994.

3 Procedência, umidade de entrada na indústria e resultados da contaminação com micotoxinas das 90 amostras coletadas em agosto de 1994.

4 Número de amostras recebidas com umidade igual ou maior que $14,5 \%$ e igual ou maior que $16 \%$.

5 Contaminação média e valor máximo de contaminação, em $\mu \mathrm{g} / \mathrm{kg}$, considerando a soma das aflatoxinas $B_{1}$ e $G_{1}$, em cada amostragem.

6 Distribuição das amostras segundo a sua origem e contaminação destas por aflatoxina $B_{1}$. 
OCORRÊNCIA DE AFLATOXINAS, ZEARALENONA E OCRATOXINA A, NO MILHO, A SER UTILIZADO COMO MATÉRIA- PRIMA EM INDÚSTRIA ALIMENTÍCIA DO ESTADO DE SÃO PAULO.

\author{
Orientado: Eng $^{\circ}$ Agr $^{\circ}$ Eduardo Micotti da Gloria \\ Orientador: Prof. Dr. Homero Fonseca
}

\title{
RESUMO
}

O milho utilizado pela indústria alimentícia no Estado de São Paulo não teve, até o momento, sua qualidade avaliada quanto à presença de micotoxinas. Existem levantamentos regionais no país, mas, somente alguns envolvem o milho para consumo humano. Entretanto, o Estado de São Paulo é, historicamente, o maior importador de milho de outros Estados do país, os quais têm padrões agroclimáticos e niveis tecnológicos muito diferentes.

Este projeto de pesquisa teve como objetivo principal avaliar o milho destinado à indústria alimentícia de São Paulo quanto à presença das micotoxinas: aflatoxinas, zearalenona e ocratoxina A. Identificou-se também a procedência $e, o$ teor de umidade do milho que chega à indústria.

Esta avaliação foi feita através do levantamento da ocorrência destas micotoxinas no milho consumido por uma indústria moageira, instalada em Mogi-Guaçu-SP, que tem expressiva participação no mercado consumidor de milho e seus derivados no Estado de São Paulo.

As amostragens foram realizadas em três épocas diferentes, sendo a primeira em outubro de 1993 (96 amostras), a segunda em março de 1994(106 amostras) e a terceira em agosto de 1994 (90 amostras), totalizando 292 amostras. Os resultados das análises mostraram presença somente de aflatoxinas. $A$ ocratoxina $A$ e a zearalenona não foram detectadas. 
$A$ aflatoxina $B_{1}$ foi a toxina mais frequente, tendo sido detectada em $57,3 \%, 16,0 \%$ e $27,7 \%$ das amostras da primeira, segunda e terceira amostragens, respectivamente.

Em geral, os niveis de contaminação encontrados não foram altos, à exceção de 7 amostras nas quais os níveis excederam o limite tolerado pela legislação brasileira para a soma das aflatoxinas $B_{1}$ e $G_{1}(30 \mu \mathrm{g} / \mathrm{kg})$. A contaminação média, considerando a soma destas duas aflatoxinas, foi de $14,9 \mu \mathrm{g} / \mathrm{kg}, 13,9 \mu \mathrm{g} / \mathrm{kg}$ e $4,3 \mu \mathrm{g} / \mathrm{kg}$, na primeira, segunda e terceira amostragens respectivamente. Já o valor máximo encontrado foi de $143 \mu \mathrm{g} / \mathrm{kg}$, ocorrido na segunda amostragem (março/1994).

O registro da procedência das amostras revela que a origem dos carregamentos de milho variou entre os períodos amostrados. Na primeira, segunda e terceira amostragens $100 \%, 34,4 \%$, e $76,6 \%$ das amostras, respectivamente, eram de outros Estados do Brasil.

Os niveis de umidade das amostras foram diferentes entre as amostragens revelando que $51,0 \%$ e $66,9 \%$ e $27,7 \%$ das amostras da primeira, segunda e terceira amostragens estavam com teores de umidade acima de $14,5 \%$, nivel máximo recomendado pelo Ministério da Agricultura para comercialização do milho. 
OCCURRENCE OF AFLATOXINS, ZEARALENONE AND OCHRATOXIN A IN THE CORN UTILIZED BY THE FOOD INDUSTRY IN THE SÃO PAULO STATE.

Author: $\mathrm{Eng}^{\circ} \mathrm{Agr}^{\circ}$ Eduardo Micotti da Gloria Adviser: Prof. Dr. Homero Fonseca

\section{SUMMARY}

Corn utilized by the food industry in the São Paulo state has not yet been evaluated for mycotoxins occurrence. There are regional surveys in the country but only a few on corn for human consumption. São Paulo, historically, the state that most imports corn from other states of Brazil, which differ a lot in weather conditions and production systems.

The main objective of this research was to evaluate the corn driven to the food industry of São Paulo for the presence of the mycotoxins aflatoxins, zearalenone and ochratoxin $A$ and also, identify its origin and register moisture levels of the loadings arriving at the industry.

This survey was carried out in a corn milling industry, installed in state of São Paulo, which has an expressive participation in corn and its related products commercialization in the São Paulo state.

The samples were withdrawn in three different periods, the first being, in October 1993(96 samples), second in March 1994(106 samples) and third in August 1994 (90 samples), accounting 292 samples. The results of analysis showed that only aflatoxins but not zearalenone or ochratoxin $A$ were detected in corn.

Aflatoxin $B_{1}$ was the most freaquent toxin detected, $57.3 \%, 16.0 \%$ and $27.7 \%$, of the samples in the first, second and third samplings, respectively. 
The levels of aflatoxin $B_{1}$ contamination found were not high, except 7 samples which showed higher levels than the Brazilian tolerance limit for aflatoxins $B_{1}+G_{1}(30 \mu \mathrm{g} / \mathrm{kg})$. The average contamination found for aflatoxins $B_{1}+G_{1}$ was of $14.9 \mu \mathrm{g} / \mathrm{kg}, 13.9 \mu \mathrm{g} / \mathrm{kg}$ and $4.3 \mu \mathrm{g} / \mathrm{kg}$ in the first, second and third samplings, respectively. The higher level of contamination was $143 \mu \mathrm{g} / \mathrm{kg}$ in second sampling (March/1994).

The procedence registration of samples showed that it varied among samplings. The first, second and third sampling had $100 \%, 34.4 \%$ e $76.6 \%$ of samples coming from other states of Brazil.

The corn moisture levels were different among samplings showing that $51.0 \%, 66.9 \%$ and $27.7 \%$ of samples in the first, second and third sampings presented moisture level above $14.5 \%$, maximun level recomended by the Ministry o Agriculture of Brazil, for trade. 


\section{INTRODUÇÃO}

O grão do milho (Zea mays L.) possui alguns nutrientes que são essenciais para o metabolismo humano e animal; talvez por isto ele tem ocupado há alguns séculos um lugar importante em suas dietas.

$\mathrm{Na}$ constituição do milho encontramos em média, $60 \%$ de carboidratos, $10 \%$ de proteinas, $4 \%$ de lipídio (FANCELLI, 1982), além de minerais e vitaminas. Esta constituição propicia que este cereal seja utilizado no preparo de mais de 500 derivados (NOGUEIRA Jr. et al., 1987), sendo a base de complexos industriais diversificados e, nos dias atuais, um relevante fator sócio-econômico para muitas regiōes do mundo.

No Brasil, o papel do milho na alimentação humana e animal é importante e antigo e, mesmo antes da chegada dos colonizadores ao país, o milho já era cultivado e utilizado pelos indígenas. Atualmente, a importância do milho, no cômputo geral da agricultura do país, traduz-se pela participação de 42,6\% das 75,2 milhões de toneladas de grãos colhidos na safra 93/94 (PREVISÃO e ..., 1994).

A industrialização do milho, para alimentação humana, divide-se basicamente em dois setores, que são os processamentos a seco e a úmido. No Brasil, ambos são responsáveis pelo consumo de cerca de $15 \%$ do total de milho consumido no pais (SETTI, 1992). 
Dos possiveis derivados do milho, os mais tradicionais e utilizados na alimentação humana, no Brasil, são a canjica, a farinha e o fubá. Entretanto, novos produtos têm surgido para atender uma faixa de consumidores mais reduzida e exigente (NOGUEIRA Jr. et al., 1987).

Diante desta intensa utilização do milho, a qualidade do grão a ser utilizado diretamente, ou na forma de matéria-prima para produtos destinados à dieta humana e animal, é muito importante.

Uma das causas da inevitável perda de qualidade dos grãos de cereais armazenados pode ser, dentre várias outras, a contaminação fúngica dos grãos. Com o desenvolvimento dos fungos podem ocorrer perdas nutricionais devido à transformação ou degradação de nutrientes, consumo da energia bruta, consumo da matéria seca e, o principal fator a considerar, a possibilidade de fungos toxigênicos se desenvolverem e produzir metabólitos tóxicos (micotoxinas) ao homem e aos animais (LACEY, 1989).

Atualmente, a qualidade do milho com relação a grãos trincados, ardidos, mofados, micotoxinas e resíduos tóxicos, não está garantida, porque as classificações oficiais disponiveis não controlam ou controlam mal estes fatores (SETTI, 1992). A comercialização do milho baseia-se na classificação oficial, dividida entre os tipos 1, 2 e 3 e umidade até 14,5\% e na praxe do mercado que trabalha com o milho contendo até $14 \%$ de umidade, $1 \%$ de impurezas e $6 \%$ de ardidos, o que, também, é insuficiente para garantir a qualidade dos grãos.

Dentro deste contexto, a importância de uma avaliação da situação, quanto à contaminação por micotoxinas, do milho a ser utilizado na alimentação humana no Estado de São Paulo, baseia-se no fato de que : 
a) Muitas micotoxinas já foram comprovadamente reconhecidas como causadoras de efeitos danosos (carcinogênicos, teratogênicos, mutagênicos, estrogênicos e imunossupressivos entre outros), para a saúde de muitas espécies inclusive relacionadas como causadoras de vários problemas à saúde do homem.

b) Existem condições particulares para a produção das micotoxinas, por diversas espécies de fungos, no campo ou no armazenamento. A probabilidade de que condições para produção de micotoxinas ocorram nas diversas situações de produção a que o milho é submetido é alta uma vez que, segundo MONTEIRO et al. (1992), existem 92 zonas macroecológicas de produção de milho no Brasil, onde variam os padrões climáticos e os niveis tecnológicos de cultivo, colheita e armazenamento.

c) $O$ milho produzido em diversas regiões, pode alcançar, através do comércio, locais distantes daqueles onde foi produzido elou armazenado, e trazer a contaminação por micotoxinas, para um centro consumidor onde a produção local é considerada livre deste problema.

d) No Brasil existe, historicamente, os Estados exportadores internos de milho para outros Estados, representados atualmente pelo Paraná e os Estados do Centro-Oeste, segundo COGO (1992).

O Estado do Paraná abastece sistematicamente, os Estados de Santa Catarina, Rio Grande do Sul e São Paulo. Por sua vez, os Estados produtores do Centro-Oeste abastecem São Paulo e parte do Nordeste. O maior importador interno é o Estado de São Paulo, daí a importância em avaliar também o milho importado de outros Estados e não só o produzido em São Paulo. 


\section{OBJETIVOS}

$O$ presente trabalho visou estudar a ocorrência, das aflatoxinas $B_{1}, B_{2}, G_{1}$ e $G_{2}$, zearalenona e ocratoxina $A$, no grão de milho destinado a produção de alimentos humanos, no Estado de São Paulo, através do levantamento realizado em uma indústria moageira de milho de alta significância no mercado estadual, localizada no interior de São Paulo.

Além do objetivo principal de detectar-se a ocorrência de micotoxinas no milho, este trabalho preocupou-se em identificar também a procedência dos carregamentos de milho durante os períodos de amostragem e umidade das cargas de milho, quando de sua chegada à indústria, afim de conhecer-se em que condições de umidade os grãos de milho foram transportados do seu local de origem até a indústria. 


\section{REVISÃO BIBLIOGRÁFICA}

\subsection{Aflatoxinas}

\subsubsection{Características e efeitos tóxicos}

A palavra aflatoxina é utilizada para designar um grupo de 17 substâncias químicas mas, via de regra, refere-se a quatro substâncias principais, as aflatoxinas $B_{1}, B_{2}, G_{1}$ e $G_{2}$. Estas substâncias apresentam fluorescência, azul-violeta ou esverdeada, quando submetidas à luz ultravioleta $366 \mathrm{~nm}$ e, por isso, são representadas pelas letras B ("blue") ou G ("green"). Os indices 1 e 2, referem-se à sua mobilidade cromatográfica (ORGANIZACION PANAMERICANA DE LA SALUD, 1983).

Segundo HEATHCOTE (1984), as aflatoxinas são metabólitos fúngicos secundários, que podem ser produzidos por algumas linhagens das espécies Aspergillus flavus Link ex Fries e A. parasiticus Speare. Estas substâncias são moléculas heterocíclicas, com átomos de oxigênio e com aneís de disfurano, que diferem entre si apenas por pequenas variações em sua composição e estrutura molecular.

HESSELTINE et al. (1970), relataram que linhagens da espécie $A$. flavus produzem somente aflatoxinas $B_{1}$ e $B_{2}$, enquanto, a espécie $A$. parasiticus pode produzir as aflatoxinas $B_{1}, B_{2}, G_{1}$ e $G_{2}$.

DIENER et al. (1987), observaram que a espécie $A$. parasiticus é mais adaptada ao meio ambiente do solo, sendo predominante em culturas 
como a do amendoim. Entretanto, a espécie A. flavus é mais adaptada ao ambiente aéreo sendo predominante em culturas como a do milho.

Sabe-se que a contaminação de milho com aflatoxinas é um problema tanto a nivel de campo como de armazém (LILLEHOJ, 1986).

Existe um grande número de fatores que influenciam o crescimento dos fungos toxigênicos e também a produção das micotoxinas. Segundo JARVIS (1971), a produção de aflatoxinas em um substrato natural, como o milho, é dependente de fatores fisicos tais como, temperatura, aeração, luz, danos mecânicos, tempo de armazenamento, regiōes quentes na massa de alimentos, produzidas pelo desenvolvimento de microrganismos; fatores quimícos como composição do substrato, $\mathrm{pH}$, uso de agentes fungistáticos, teor de $\mathrm{O}_{2}$ e $\mathrm{CO}_{2}$ do ambiente; fatores biológicos como linhagem toxigênica, quantidade de esporos viáveis, competição microbiana, degradação microbiana, presença de insetos e algum estresse que $o$ alimento pode sofrer.

Com a constatação de que a contaminação por aflatoxinas poderia acontecer também durante o cultivo do milho (RAMBO et al., 1974, ANDERSON et al., 1975, LILLEHOJ et al., 1976, MCMILLIAN et al., 1980 e WALLIN, 1986), descobriu-se que outros fatores influenciavam a contaminação, infecção e colonização dos grãos no campo, tais como, o nivel de infestação por insetos (BARRY, 1986), condições climáticas (SISSON, 1986), período que ocorre infecção da espiga e temperaturas altas após a infecção (JONES et al., 1980), resistência genética do cultivar (PAYNE, 1986 e WALLIN et al., 1991) e práticas culturais (JONES, 1986).

Apesar de existirem vários fatores influenciando a produção de aflatoxinas, as condições de umidade e temperatura são os que tem maior influência sobre a produção destas tanto em condições de campo (LILLEHOJ, 1986), como em condições de armazém (FORTNUM, 1986). 
NORTHOLT \& BULLERMAN (1982) relataram a influência fundamental que tem a combinação de condições de temperatura e umidade sobre o crescimento e a produção de aflatoxinas por $A$. flavus e $A$. parasiticus.

TRUCKSESS et al. (1988) estudaram o efeito da atividade de água, temperatura e presença de outros fungos toxigênicos, no crescimento de Aspergillus flavus e produção de aflatoxinas tendo como substrato o milho, em condições controladas de umidade. Nas temperaturas de $26^{\circ} \mathrm{C}$ e $32^{\circ} \mathrm{C}$ o limite mínimo de atividade de água para produção de aflatoxinas foi de $a_{w}=0,85$, o que normalmente equivale à um teor de umidade de $16 \%$. Para o crescimento fúngico contudo, o limite mínimo de atividade de água foi de $a_{w}=0,73$. $\mathrm{Na}$ temperatura de $16^{\circ} \mathrm{C}$ não houve produção de aflatoxina mesmo com atividade de água $a_{w}=0,96$.

Com relação aos efeitos tóxicos das aflatoxinas verificou-se segundo CARNAGHAN et al. (1963) e WOGAN (1966), que as quatro principais aflatoxinas apresentam o seguinte grau de toxidade $B_{1}>G_{1}>B_{2}>G_{2}$.

Segundo SCHIMIDT \& ESSER (1985), a aflatoxina $B_{1}$ é o composto mais tóxico e tem maior incidência dentro do grupo das aflatoxinas, podendo provocar intoxicações agudas e crônicas.

Segundo BRADBURN et al. (1993), a intoxicação crônica inclui três tipos de atividade; carcinogênica, mutagênica e teratogênica.

Segundo HSIEH et al. (1977), as espécies animais variam muito em sua suscetibilidade aos efeitos agudos e crônicos da aflatoxina $B_{1}$ e, os efeitos tóxicos, dentro da mesma espécie, podem ser influenciados por fatores ambientais, estado nutricional, saúde, idade sexo do animal e ainda, segundo ALMEIDA (1994), a via de administração e a capacidade do animal de biotransformar a toxina.

O efeito tóxico crônico das aflatoxinas em humanos, como consequência da ingestão de teores sub-agudos de aflatoxinas, por longos períodos de tempo, vem sendo estudado principalmente, através de dados 
epidemiológicos que tentam correlacionar o consumo de alimentos contaminados com aflatoxinas, presente na dieta de humanos, e a taxa de incidência do câncer hepático em certas regiōes do mundo (CAMPBELL \& STOLOFF, 1974 e SHANK, 1978).

Segundo HAYES (1981), evidências epidemiológicas tem sugerido as aflatoxinas como causadoras de câncer em humanos, particularmente do câncer hepático. Vários trabalhos, relacionando distúrbios hepáticos com dietas humanas contendo altos niveis de aflatoxinas, surgiram em Uganda, Taiwan, Quênia, Suazilândia, Moçambique, Filipinas, Sudeste da Ásia, Senegal e Índia. À exceção dos dados originários da Índia, segundo o autor, todos os outros estudos apresentam evidências que indicam a relação positiva entre o aparecimento de hepatocarcinoma primário e a exposição às aflatoxinas (MEHAN et al., 1991).

Os primeiros estudos epidemiológicos realizados são criticados por não estimarem a exposição individual às aflatoxinas (MEHAN et al., 1991). Estudos mais recentes por sua vez, são questionados por terem trabalhado com populações de regiōes hoje sabidamente endêmicas ao vírus da hepatite tipo B, um fator que tem dificultado os estudos da determinação do verdadeiro agente etiológico do hepatocarcinoma primário (STOLOFF, 1989).

Alguns estudos foram executados com o objetivo de avaliar a relação entre a presença do vírus da hepatite $B$ e a exposição às aflatoxinas, na determinação da incidência de câncer hepático.

VAN RENSBURG (1977), PEERS et al. (1987) e YEH et al.(1989), concluiram que pelos dados obtidos em seus estudos não havia uma relação entre a ocorrência do virus da hepatite $B$ e a incidência de câncer hepático, mas a incidência de câncer hepático estava fortemente correlacionada com a exposição às aflatoxinas.

Entretanto, STOLOFF (1985, 1989) e CHEN et al. (1990) concluiram em seus trabalhos que 0 aparecimento do hepatocarcinoma 
primário em humanos, é determinado pela presença do vírus da hepatite tipo B e não pela exposição às aflatoxinas.

Apesar da controvérsia que existe, já em 1987, o grupo de trabalho da Agência Internacional para Pesquisa sobre Câncer (IARC), estabeleceu que a aflatoxina pode ser considerada como uma provável substância carcinogênica para humanos segundo MYCOTOXINS (1989).

A relação da ingestão das aflatoxinas, através de alimentos, com a etiologia de conhecidas doenças, tais como, kwashiorkor, cirrose infantil indiana e a sindrome de Reye também vem sendo estudada como uma possivel conseqüência da ingestão de alimentos contaminados (MEHAN et al., 1991).

Devido à semelhança entre os sintomas da doença denominada sindrome de Reye, que atinge a população humana de certas regiōes da Europa e a aflatoxicose aguda em macacos, BOURGEOIS et al. (1971) e VAN RENSBURG (1977) relacionaram a sindrome de Reye com a ingestão de alimentos contaminados com aflatoxinas. BECROFT \& WEBSTER (1972) por terem encontrado as aflatoxinas $B_{1}$ e $G_{1}$, no extrato do fígado de vítimas da sindrome de Reye, também fizeram essa relação.

Contudo, não existe atualmente dados conclusivos na literatura sobre a verdadeira relação das aflatoxinas com a etiologia da sindrome de Reye.

A presença de aflatoxina no fígado de crianças vítimas do Kwashiorkor e do Kwashiorkor marásmico foi relatada por HENDRICKSE (1984) e COULTER et al. (1986). Baseados nestes estudos HENDRICKSE (1984) e PEARSON (1990), postularam que o kwashiorkor poderia ser resultado do envenenamento crônico por aflatoxinas.

A possivel relação da doença denominada Cirrose infantil indiana, como sendo uma intoxicação crônica por aflatoxinas foi feita por AMLA et al. (1970 e 1971), que mostraram que crianças expostas as aflatoxinas através do 
leite materno devido a exposição das mães a ítens da dieta tais como, óleo de amendoim não refinado e arroz parbolizado, altamente contaminados, puderam desenvolver cirrose. Contudo, MEHAN et al. (1991), discutindo os trabalhos de AMLA et al. (1970 e 1971) não encontraram relação entre a ingestão de aflatoxina e o aparecimento da cirrose infantil indiana. Segundo os autores, esta última doença não ocorre em todas as regiões onde componentes da dieta humana acham-se contaminados com altos teores de aflatoxinas.

Quanto à intoxicação aguda por aflatoxinas em humanos, SHANK (1978), mostra os dados provenientes de intoxicações ocorridas em Taiwan e Uganda como sendo os primeiros casos positivos. No estudo de Taiwan foram relatadas como vítimas, crianças que pertenciam a um grupo de famílias que plantaram e colheram seu próprio arroz que estava preto e mofado, mas mesmo assim foi consumido por estas durante pelo menos três semanas antes do aparecimento dos sintomas da doença. $A$ contaminação por aflatoxina $B_{1}$ no arroz foi de aproximadamente $200 \mu \mathrm{g} / \mathrm{kg}$. Fato semelhante ocorreu em Uganda envolvendo uma criança. Entre outros alimentos consumidos pelo paciente e sua família, foi encontrada mandioca contaminada com altos niveis de aflatoxina $B_{1}(1700 \mu \mathrm{g} / \mathrm{kg})$.

Outros três relatos de aflatoxicose aguda em humanos citados em literatura, envolvendo o consumo de milho fortemente mofado, ocorreram na Índia (KRISHNAMACHARI et al., 1975 a,b) e no Quênia (NAGINDU et al., 1982). Na Índia ocidental um milho muito mofado e contaminado com aflatoxinas foi utilizado para alimentar a população de mais de $\mathbf{2 0 0}$ vilas que apresentaram, posteriormente, um quadro de icterícia epidérmica onde, de 397 pacientes internados, houve 106 óbitos precedidos de hemorragia gastrointestinal. A contaminação encontrada no milho foi de 6 a $16 \mathrm{mg} / \mathrm{kg}$ de aflatoxinas com a estimativa de ingestão diária de aflatoxina por pessoa de $6 \mathrm{mg}$. 
No Quênia, uma possivel aflatoxicose aguda foi associada ao consumo de milho fortemente contaminado por aflatoxinas. Em 1981, 20 pacientes com hepatite, 12 dos quais morreram, foram admitidos em hospitais no distrito de Macacos, no Quênia. Dos 12 membros de uma família 8 morreram após à ingestão de milho contendo, aproximadamente $12.000 \mu \mathrm{g} / \mathrm{Kg}$ de aflatoxina $B_{1}$. $O$ tecido do fígado necropciado continha acima de $89 \mu \mathrm{g} / \mathrm{Kg}$ de aflatoxina $B_{1}$.

Embora exista ainda bastante controvérsia sobre o efeitos da aflatoxina na saúde humana, muitos paises, segundo VAN EGMOND (1993), adotaram limites máximos permitidos para presença de aflatoxinas em alimentos.

No Brasil, a presença das aflatoxinas nos alimentos é regulada pela resolução $n^{0} 34 / 76$ do CNNPA que estabelece o limite máximo de 30 $\mu \mathrm{g} / \mathrm{kg}$, para somatória das aflatoxinas $B_{1}$ e $G_{1}$ (BRASIL, 1977).

\subsubsection{Ocorrência}

De acordo com BULLERMAN et al. (1984) e LACEY (1989), a produção de aflatoxinas pelos fungos aflatoxigênicos é controlada por uma série de fatores ambientais, relacionados entre si, e também pela própria suscetibilidade do substrato.

TRENK \& HARTMAN (1970), MARTIN \& GILMAN (1976) e BULLERMAN et al. (1984), citam o grão de milho como um substrato apropriado ao crescimento de espécies aflatoxigênicas e conseqüentemente à produção de aflatoxinas.

Segundo JELINEK (1988), os estudos de ocorrência de contaminação por aflatoxinas dos diversos produtos agrícolas, mostram que os três produtos mais suscetiveis à contaminação por aflatoxinas são em ordem decrescente o amendoim, o milho e a semente de algodão. 
Segundo SMITH \& MOSS (1985), o milho nos Estados Unidos da América, constituiu-se na principal fonte de entrada de micotoxinas na dieta humana, em particular as aflatoxinas, zearalenona e ocratoxina $A$.

Vários trabalhos tem mostrado a ocorrência de aflatoxinas no milho em diversas regiōes do mundo.

SHOTWELL et al. (1970), avaliaram 283 amostras de milho provenientes de alguns Estados, nos Estados Unidos da América, na safra de 1967 para a presença de aflatoxinas $B_{1}$ e $G_{1}$ e encontraram 6 amostras contaminadas com niveis de aflatoxina $B_{1}$.entre $12-25 \mu \mathrm{g} / \mathrm{kg}$.

NAKAZATO et al. (1982), avaliaram a ocorrência das aflatoxinas $B_{1}, B_{2}$ e citrinina, em grãos de cereais e outros produtos processados na cidade de Tokio, no Japão. Dentre as 94 amostras analisadas 11 amostras de farinha de milho apresentavam contaminação por aflatoxinas $B_{1} \cdot B_{2}$ e citrinina.

DVALI (1983) pesquisou aflatoxinas em 619 amostras de cereais e vegetais na república da Georgia, na antiga U.R.S.S., encontrando 7 entre 162 amostras de milho, contaminadas por aflatoxina $B_{1}$. A maior concentração entre os produtos foi encontrada no milho ao nivel de $600 \mu \mathrm{g} / \mathrm{kg}$.

CARDENAS \& PLATA (1986), estudaram a contaminação por aflatoxinas do milho branco e amarelo armazenado em fazendas, armazéns, moinhos produtores de farinha e outras indústrias processadoras em vários locais da província de Meta, na Colômbia. Os dados deste estudo mostraram uma alta incidência de aflatoxina. Em $91,7 \%$ das amostras a contaminação atingiu niveis acima de $20 \mu \mathrm{g} / \mathrm{kg}$.

SANCHIS et al. (1986), na Espanha, analisaram um total de 338 amostras de alimentos e rações, encontrando entre as amostras de milho a maior frequiência de contaminação assim como, de fungos aflatoxigênicos.

Os trabalhos de avaliação da contaminação por aflatoxinas em alimentos destinados a seres humanos no Brasil iniciaram-se no final da década de 60 principalmente, com a investigação da ocorrência no amendoim 
FONSECA (1969), PREGNOLATTO \& SABINO (1969) e FONSECA \& DEL NERY (1970).

Estudos de KUSHALAPPA (1979), FONSECA et al. (1982), FONSECA et al. (1983), PRADO (1983), SABINO et al. (1986), FIORENTINI et al. (1989), SABINO et al. (1989) sobre a ocorrência de aflatoxinas no milho e seus produtos começaram no Brasil de forma incipiente no final da década de 70 e foram um pouco mais freqüentes na década de 80 . Contudo, a provável utilização para o milho não foi citada e as amostragens realizadas não consideraram a variação sazonal da origem do milho.

Alguns trabalhos realizados no Brasil pesquisaram o milho e/ou seus produtos, destinados, exclusivamente à alimentação humana, com o objetivo de detectar aflatoxinas.

PRADO (1983) analisou 177 amostras, sendo 32 amostras de farinha de milho e outros produtos a base de milho, as quais foram retiradas do comércio em Belo Horizonte. Não foram detectadas aflatoxinas em nenhuma das amostras.

O trabalho de SCUSSEL (1984) verificou a possibilidade de contaminação do milho no campo, em três estágios de maturação e também em 83 amostras de milho, farinha de milho amarela e branca, milho verde, fubá, flocos de milho cozido e sêmola, da região de Campinas, SP. Os resultados mostraram que não houve contaminação por aflatoxinas.

SOARES \& RODRIGUES-AMAYA (1989), investigaram a presença de aflatoxinas em 296 amostras de diversos produtos, dentre os quais 130 amostras de 8 tipos de produtos a base de milho, retiradas aleatoriamente do mercado de varejo da cidade de Campinas, SP. Entre as amostras de milho e produtos derivados, as aflatoxinas foram encontradas somente em amostras de milho pipoca em niveis entre 20 a $47 \mu \mathrm{g} / \mathrm{kg}$.

VALE et al. (1990), estudaram, em Fortaleza, a contaminação do milho e seus derivados com aflatoxinas. Os autores verificaram que a maioria 
das 100 amostras estavam contaminadas com mais de $30 \mu \mathrm{g} / \mathrm{kg}$, considerandose a soma das aflatoxinas $B_{1}$ e $G_{1}$.

BALDISSERA et al. (1992), investigaram a incidência de aflatoxinas em amendoim e farinha de milho. Foram analisadas 61 amostras de farinha de milho, destinadas ao consumo humano, originárias de 21 marcas comerciais diferentes adquiridas no comércio de Santa Maria-RS, no periodo de abril a novembro de 1991. Das amostras analisadas $81,9 \%$ foram positivas para aflatoxinas, sendo que somente $6,5 \%$ apresentavam valores de contaminação acima do limite de $30 \mu \mathrm{g} / \mathrm{kg}\left(B_{1}+G_{1}\right)$. A maior concentração encontrada foi de $68 \mu \mathrm{g} / \mathrm{kg}$.

YAHL et al. (1971), estudaram distribuição da contaminação por aflatoxinas nos sub-produtos do processamento à úmido do milho e verificaram que a maior parte da contaminação concentrava-se na água de maceração e sub-produtos para ração animal. A água de maceração apresentou $39-42 \%$ da contaminação final total detectada nos sub-produtos. As fibras continham de $30-38 \%$ e o glutém $14-17 \%$ da contaminação final. O amido, em média, apresentava $1 \%$ da contaminação final. Os niveis encontrados foram 4 a 5 vezes maior que o nivel original de contaminação do milho para a água de maceração, 2,5 a 3 vezes para as fibras e 1 a 1,5 para o glutém. BENNETT \& ANDERSON (1978) encontraram os mesmos resultados em seus estudos.

Através dos estudos de YAHL et. al. (1971) e BENNETT \& ANDERSON (1978), conclui-se que em estudos de ocorrência de contaminação de milho e/ou seus sub-produtos é importante observar o tipo de processamento que os grãos foram ou serão submetidos. Certos produtos produzidos a partir de alguns constituintes do grão de milho podem não apresentar niveis detectáveis de aflatoxinas mesmo que tenha-se utilizado milho contaminado para sua fabricação. Entretanto, outros produtos podem apresentar niveis de contaminação bem acima dos niveis originais detectados no milho. 
JELINEK et al. (1989) reuniram dados da contaminação do milho e produtos do milho de 16 paises e ressaltaram a variação dos niveis encontrados que pode haver de ano para ano e de uma região para outra dentro de um mesmo pais.

Nos Estados Unidos da América, segundo WOOD (1992), o milho vem sendo monitorado, quanto à presença das aflatoxinas, desde 1965, e hoje existem dados suficientes para localizar o problema da contaminação, por regiões produtoras. Mas mesmo assim, o "Food and Drug Administration" (FDA), organismo do ministério da saúde americano, realiza permanentemente - controle da qualidade do milho comercializado entre os Estados daquele país. CELARO (1992), relatou que as condições de colheita e pós-colheita, a que o milho pode ser submetido no Brasil, são bastante precárias.

Entretanto as avaliações da contaminação do milho e de seus produtos destinados a alimentação humana no Brasil são escassas, inconstantes, e restritas a poucas regiōes consumidoras ou produtoras.

\subsection{Zearalenona}

\subsubsection{Características e efeitos tóxicos}

A zearalenona é um metabólito secundário, descoberto em culturas de Giberela zeae, o estágio sexual ou perfeito do Fusarium graminearum, que foi isolado de milho embolorado ao qual foi atribuido a ocorrência de uma sindrome estrogênica em alguns suinos (STOB et al., 1962).

Quimicamente a zearalenona é uma lactona de ácido fenólico resorcílico que apresenta uma fluorescência azul esverdeada, quando é excitada com luz ultra violeta de ondas longas $360 \mathrm{~nm}$ e uma fluorescência verde mais intensa quando é excitada com luz ultravioleta de ondas curtas de 254nm (ORGANIZACION PANAMERICANA DE LA SALUD, 1983). 
Segundo JOFFE (1986), a zearalenona e seus derivados naturais são produzidos por várias espécies de Fusarium entre elas $F$. graminearum, sub-espécies ( $F$. avenaceum, $F$. culmorum, $F$. equiseti, $F$. gibosum), $F$. lateritium, F. moniliforme, F. oxysporum, F. sambucinum, $F$. solani, $F$. sporotrichioides e F. tricinctum.

EUGENIO et al. (1970), estudaram a produção de zearalenona por Fusarium graminearum em alguns substratos naturais e observaram que a produção máxima de zearalenona foi conseguida a temperaturas entre $10^{\circ} \mathrm{C} \mathrm{e}$ $20^{\circ} \mathrm{C}$. Para o milho incubado a $22-25^{\circ} \mathrm{C}$ por 2 semanas e depois a $12^{\circ} \mathrm{C}$ por 8 semanas a maior produção de zearalenona foi alcançada com uma umidade próxima de $45 \%$. Observaram, também, que a produção de zearalenona por $F$. graminearum, na presença de outros fungos, foi bastante afetada.

Segundo KUIPER-GOODMAN et al. (1987), vários estudos confirmaram que a zearalenona, para ser produzida pelas espécies de Fusarium, necessita que o fungo sofra um estresse após o periodo de crescimento. Normalmente, o estresse é provocado por um regime de temperatura especial, que consiste na permanência do ambiente, onde o fungo cresce, a temperaturas de $24-25^{\circ} \mathrm{C}$, por 7 a 15 dias, suscedido pelo abaixamento da temperatura a niveis de $10-12^{\circ} \mathrm{C}$ por 30 a 60 dias.

Segundo MIROCHA \& CHRISTENSEN (1974), as enzimas envolvidas na biossintese da zearalenona são induzidas ou ativadas a baixas temperaturas $\left(12-14^{\circ} \mathrm{C}\right)$, uma temperatura que não é ótima para o crescimento dos fungos produtores.

SHERWOOD \& PEBERDY (1974), notaram que a umidade dos grãos foi fator de maior influência no estabelecimento de Fusarium em grãos de milho, trigo, aveia e cevada, mas a temperatura afetou diretamente a sintese de zearalenona. Todos os substratos, testados pelos autores, foram suscetiveis à invasão por Fusarium nos niveis de umidade acima de $18 \%$, ainda quando o armazenamento foi a $7^{\circ} \mathrm{C}$. Na faixa de $15 \%$ a $18 \%$ de umidade, aumentava o 
risco da contaminação dos grãos com o aumento da temperatura. As produções máximas de zearalenona $(500 \mu \mathrm{g}$ a $2.000 \mu \mathrm{g} / \mathrm{g}$ de grão), foram obtidas entre temperaturas de $12^{\circ} \mathrm{C}$ e $18^{\circ} \mathrm{C}$, ainda que o crescimento micelial tenha sido reduzido. $\mathrm{A} 25^{\circ} \mathrm{C}$ o crescimento micelial foi rápido, mas a produção de toxina raramente ultrapassou $100 \mu \mathrm{g} / \mathrm{g}$ de grão.

MIROCHA et al. (1980), citam que encontraram maior produção de zearalenona, trabalhando com Fusarium graminearum "Gibbosum", em arroz a temperatura constante de $25^{\circ} \mathrm{C}$.

MIROCHA \& CHRISTENSEN (1974), relataram que os suínos são os animais mais suscetiveis aos efeitos da zearalenona. Sob condições experimentais, fêmeas de suinos com 6 semanas de vida foram expostas, por via oral, a uma dose de $5 \mathrm{mg}$ por animal por dia durante 5 dias e desenvolveram aumento da vulva, mamas e o prolapso da vagina. Os sintomas foram reversiveis no término da exposição.

De acordo com WORLD HEALTH ORGANIZATION (1979), não há relatos de efeitos adversos da zearalenona no homem.

Segundo KUIPER-GOODMAN et al. (1987), a IARC colocou a zearalenona na categoria de limitada evidência de carcinogenicidade e recomendou que mais estudos sejam realizados para confirmar a zearalenona como uma substância potencialmente carcinogênica para seres humanos.

Segundo MIROCHA et al. (1980), não existe informação direta do efeito da zearalenona na saúde dos humanos. Entretanto, um derivado da zearalenona, o zearalenol, foi comercializado na Itália como um agente estrogênico com o nome de FRIDERON, para aliviar o desconforto da menopausa em mulheres. Esta terapia em humanos recomendava até 75 $\mathrm{mg} / \mathrm{dia}$ e pouco ou nénhum efeito colateral foi observado.

No ponto de vista de KUIPER-GOODMAN et al. (1987), com base nos conhecimentos disponiveis, sobre os efeitos tóxicos da zearalenona em 
diversos țipos de animais, uma dose diária de $0.1 \mu \mathrm{g} / \mathrm{kg}$ de peso corpóreo para humanos seria o aceitável.

Segundo POHLAND (1993), a zearalenona tem sua presença em alimentos regulada pela legislação em pelo menos 4 paises, com os valores de contaminação permitido variando de 30 a $1000 \mu \mathrm{g} / \mathrm{kg}$.

No Brasil, não existe legislação regulando a presença de zearalenona tanto em alimentos para o homem como em rações animais.

\subsubsection{Ocorrência}

JOFFE (1986) analisando os dados de 52 esiudos sobre a contaminação natural com zearalenona em diversos produtos naturais, observou que, $50 \%$ desses referiam-se ao milho como substrato contaminado.

EUGENIO et al. (1970), estudaram a produção de zearalenona por Fusarium graminearum em alguns substratos naturais e obtiveram uma produção de zearalenona em nivel decrescente, na seguinte ordem; arroz polido e parbolizado, milho, trigo, arroz integral, aveia e cevada. Nenhuma produção foi detectada em soja e ervilha.

KOUDELA et al. (1990), observaram que a maioria dos dados de ocorrência de zearalenona mostram o milho como o produto mais sensivel a contaminação por espécies de Fusarium.

A ocorrência de zearalenona em milho tem sido bastante relatada em diversas partes do mundo e, na maioria das vezes, envolve casos de hiperestrogenismo em animais, principalmente suinos. Entretanto, também existem relatos da contaminação de outros alimentos com zearalenona.

De acordo com EPPLEY et al. (1974), em 1972 as condições climáticas nos Estados Unidos foram favoráveis à ocorrência da podridão da espiga por Fusarium. A zearalenona foi encontrada em $17 \%$ do total de 223 amostras de milho, em niveis de 0,1 até $5,0 \mathrm{mg} / \mathrm{kg}$. Dentre estas amostras, 6 
que estavam contaminadas a niveis de 0,2 a $0,5 \mathrm{mg} / \mathrm{kg}$, destinavam-se para utilização como alimento.

LOVELACE \& NYATHI (1972), analisaram cervejas elaboradas à partir de milho no Zâmbia e encontraram zearalenona em concentrações de 0,09 a 4,6 mg/l de cerveja com a concentração média de 0,92 mg/l. Segundo os autores, em algumas partes do Zâmbia o consumo "per capita" diário estimado de zearalenona, por pessoa, poderia ser de $0,45 \mathrm{mg}$ para as províncias do sudeste do país e de $0,17 \mathrm{mg}$ para a área urbana da cidade de Lusaka.

MUNHOZ et al. (1990), analisaram o milho da região da Galícia (Noroeste da Espanha), onde o cultivo do milho é uma atividade de significante importância econômica. As micotoxinas zearalenona, aflatoxinas, toxina T-2, deoxinivalenol e diacetoxiscirpenol foram pesquisadas em 55 amostras de milho retiradas do campo e 155 amostras retiradas dos "horreos" (construções destinadas ao armazenamento da produção das safras), sendo 110 em 1984 (safra de 1983), 20 em 1985 (safra de 1984) e 25 em 1986 (safra de 1985). As amostras do campo estavam com $25-35 \%$ de umidade e as dos "horreos" com 15-20\%. Zearalenona e deoxinivalenol foram as duas toxinas encontradas, sendo a zearalenona a de maior ocorrência. Nas amostras retiradas do campo não houve contaminação com zearalenona enquanto nas amostras dos "horreos" sempre houve contaminação.

Uma avaliação efetuada no Canadá entre 1979 e 1981 mostrou que, 22 amostras continham niveis de zearalenona maiores de $30 \mathrm{ng} / \mathrm{g}$ entre 104 amostras de milho ou produtos de milho, destinados ao uso como alimento. A concentração média estimada foi de $39,2 \mathrm{ng} / \mathrm{g}$ entre os produtos de cereal para café a base de milho (KUIPER-GOODMAN et al., 1987).

Uma característica importante da ocorrência da zearalenona é a co-ocorrência com outras micotoxinas. No milho a zearalenona tem ocorrido com; deoxinivalenol e toxina T-2 segundo JELINEK et al. (1989), e aflatoxina e ocratoxina A segundo BENNETT \& SHOTWELL (1979). 
No Brasil, os primeiros estudos de ocorrência de micotoxinas envolvendo a zearalenona iniciaram na década de 80 . Contudo trabalhos abordando a contaminação com zearalenona do milho destinado ao consumo humano são bastante raros.

FONSECA et al. (1982 e 1983) durante um estudo de dois anos, em 1981 e 1982, analisaram aflatoxinas, zearalenona e ocratoxina $A$ em 742 amostras de diversos produtos, retirados de prateleiras de supermercados de algumas regiões no Estado de São Paulo, entre os quais, 128 amostras de milho. A zearalenona e a ocratoxina $A$ não foram encontradas em nenhuma das 128 amostras de milho. Não havia referência sobre o provável uso do milho amostrado.

SABINO et al. (1986), pesquisaram a ocorrência de zearalenona entre outras micotoxinas no milho em grão, colhido no Estado de Minas Gerais, na safra de 1984. Entre 83 amostras analisadas, somente uma apresentava contaminação por zearalenona ao nivel de $126 \mu \mathrm{g} / \mathrm{kg}$. Neste trabalho também não havia referência a provável utilização do milho.

SOARES \& RODRIGUES-AMAYA (1989), analisaram 130 amostras de milho e seus produtos, destinados ao consumo humano, onde nenhuma amostra apresentou contaminação por zearalenona.

SABINO et al. (1989) analisaram 328 amostras de grãos de milho, sem utilização definida, proveniente dos Estados de Santa Catarina, Minas Gerais, São Paulo, Parana, Rio Grande do Sul e Espirito Santo, coletadas entre 1985 e 1986. Níveis detectáveis de zearalenona foram encontrados em $4.5 \%$ das amostras com os niveis variando entre 633 a $9830 \mu \mathrm{g} / \mathrm{kg}$.

PRADO et al. (1992), analisaram a ocorrência de aflatoxinas, ocratoxina A, esterigmatocistina e zearalenona em milho, no Estado de Minas Gerais, safra 1991, sem utilização definida, em pós-colheita e durante o armazenamento. Não foram detectadas micotoxinas nas 41 amostras ànalisadas. 
SOARES \& FURLANI (1992) analisando milho pipoca amostrado na região de Campinas, detectaram entre 227 amostras analisadas, apenas uma amostra com contaminação por zearalenona, ao nivel de $462 \mu \mathrm{g} / \mathrm{kg}$.

A presença de milho contaminado por zearalenona, no comércio do Estado de São Paulo, possivelmente seja devida a duas situações: através do milho armazenado em condições precárias as quais podem provocar a elevação da umidade da massa de grãos e favorecer o crescimento de espécies de Fusarium que posteriormente podem ter condições de temperatura adequadas a produção de zearalenona e, também, através do milho importado de regiōes (principalmente região Sul), onde as condições climáticas são mais propícias à produção da zearalenona (SABINO et al., 1989; BALDISSERA et al., 1992).

\subsection{Ocratoxina A}

\subsubsection{Características e efeitos tóxicos}

As ocratoxinas são definidas como um grupo de 7 isocumarinas unidas por uma ligação amida ao grupo amino de uma L-ß-fenilalanina, segundo HALD (1989).

De acordo com a ORGANIZACION PANAMERICANA DE LA SALUD (1983) o grupo das ocratoxinas envolve 7 compostos estruturalmente semelhantes que incluem a ocratoxina $A$, a ocratoxina $B$, a ocratoxina $C$ e ésteres metílicos e etílicos das ocratoxinas A e B.

A primeira substância descoberta, pertencente ao grupo foi a

ocratoxina $A$, isolada de uma linhagem de Aspergillus ochraceus, em laboratório. A ocratoxina A é, também, o membro mais tóxico do grupo (MOREAU, 1979).

KROGH (1977), define as ocratoxinas como um grupo de metabólitos secundários, que podem ser produzidos por 6 espécies de fungos 
do gênero Penicillium e 7 espécies do gênero Aspergillus, sendo A. ochraceus (hoje denominada, segundo MARQUARDT \& FROHLICH (1992), como $A$. alutaceus Berkeley et Curtis), Penicillium viridicatum, $P$. palitans e $P$. cyclopium, as principais espécies produtoras.

Entretanto, segundo MARQUARDT \& FROHLICH (1992) as únicas espécies confirmadamente produtoras de ocratoxina $A$ são Penicillium verrucosum e $A$. alutaceus.

Segundo STEYN (1984), a espécie A. ochraceus e membros do grupo $A$. ochraceus são provavelmente os mais importantes produtores de ocratoxinas em regiōes tropicais e semi-tropicais. Das várias espécies de Penicillium, a espécie $P$. viridicatum mostra ser predominante em regiōes frias.

MARQUARDT \& FROHLICH (1992), observaram que a produção de ocratoxina $A$ é afetada por fatores como, atividade de água, temperatura, tipo de substrato, presença de microbiota competitiva, linhagem do fungo e integridade do grão.

Segundo SCHINDLER \& NESHEIN (1970) a produção de ocratoxina $A$ por $A$. ochraceus é máxima nas temperaturas entre 20 e $30^{\circ} \mathrm{C}$.

NORTHOLT et al. (1979), testaram os efeitos da atividade de água e temperatura no crescimento e produção de ocratoxina $A$ por linhagens de $A$. ochraceus, Penicillium cyclopium, e $P$. viridicatum em substrato artificial. $O$ valor mínimo de atividade de água, para produção de ocratoxina $A$ por $A$. ochraceus, $P$. cyclopium, e $P$. viridicatum, ficou entre 0,83 e $0,87,0,87$ e 0,90 e 0,83 e 0,86 , respectivamente. Para $24^{\circ} \mathrm{C}$, os valores ótimos de atividade de água para produção de ocratoxina $A$ por $A$. ochraceus e $P$. cyclopium foram 0,99 e 0,95 0,99 , respectivamente, enquanto que, para $P$. viridicatum, ficou entre 0,95 e 0,99 para as duas linhagens testadas. Sob valores de atividade de água ótimos a faixa de temperatura em que houve produção de ocratoxina $A$ foi de $12-37^{\circ} \mathrm{C}$, para $A$. ochraceus e de 4 a $31^{\circ} \mathrm{C}$ para $P$. viridicatum e $P$. cyclopium. $O$ valor mínimo de atividade de água para crescimento micelial das linhagens, ficou 
entre 0,79 e 0,83 , não tendo havido diferença significativa entre as linhagens. A faixa de temperatura que permitiu o crescimento micelial foi de $8-37^{\circ} \mathrm{C}$ para $A$. ochraceus e $0-31^{\circ} \mathrm{C}$ para $P$. viridicatum e $P$. cyclopium.

Com relação aos aspectos toxicológicos, segundo KROGH (1977), em condiçōes experimentais já foi verificada nefropatia, induzida por ocratoxina A, em 7 espécies animais, incluindo mamíferos, pássaros e peixes. Células de rins de macacos, expostas à ocratoxina $A$ desenvolveram aumento do nucléolo e degeneração não específica. Observou-se também que, efeitos não relacionados aos rins, somente são obtidos em altos niveis de exposição e que, portanto, o rim é o único órgão afetado quando a exposição corresponde aos niveis de ocorrência de ocratoxina $A$ encontrados na natureza uma vez que, estes normalmente ocorrem a niveis baixos.

A suscetibilidade das espécies de animais varia quanto aos efeitos agudos da ocratoxina $A$, apresentando valores de $\mathrm{DL}_{50}$ ( $\mathrm{mg} / \mathrm{kg}$ de peso vivo) na faixa de 3,4 até 30,3 (WORLD HEALTH ORGANIZATION, 1979).

MIROCHA et al. (1980) observaram que a ocratoxina $A$ tem efeito sobre alguns orgãos, particularmente os rins e o fígado, onde podem causar necrose tubular dos rins e degeneração moderada do fígado.

De acordo com HAYES (1981), a ocratoxina A tem sido relatada como capaz de induzir tumores em animais de laboratório e de ser teratogênica e nefrotóxica.

STEYN (1984) relata estudos efetuados na Dinamarca e Suécia nos quais se observaram o envolvimento comprovado da ocratoxina $A$ com a nefropatia endêmica em suínos, provocada pela presença da ocratoxina $A$ em raçōes.

A nefropatia endêmica dos Bálcãs, uma doença renal fatal e associada quase sempre com tumores no sistema urinário, é ainda de etiologia desconhecida. Esta doença atinge populaçōes humanas de zonas rurais, residentes no vale do rio Danúbio, na lugoslávia, Romênia e Bulgária. Contudo, 
segundo HALD (1989), tem sido sugerido que a ocratoxina A possa ser o agente causal desta endemia nefropática, devido à semelhança com a nefropatia endêmica em suínos induzida pela ocratoxina $A$

\subsubsection{Ocorrência}

SHOTWELL et al. (1969) foram os primeiros a relatarem em, 1969, a ocorrência natural de ocratoxina $A$, em milho, nos Estados Unidos da América.

RIBELIN (1978) observou a ocorrência natural da ocratoxina A entre os seguintes produtos; milho, aveia, soja, trigo sarraceno, cevada, centeio, arroz, sorgo, feijão, amendoim, castanha do Pará, entre outros

PETKOVA-BOCHAROVA \& CASTEGNARO (1985), tentando elucidar o envolvimento da ocratoxina $A$ na etiologia da nefropatia endêmica dos Bálcãs e tumores do sistema urinário, pesquisaram a ocorrência desta micotoxina em alimentos básicos das populações daquela região. Foram analisadas 130 amostras de alimentos que incluiam feijão, milho e farinha de trigo. A ocratoxina $A$ foi encontrada somente em amostras de feijão e milho. $A$ faixa de concentração de ocratoxina $A$, em $7,1 \%$ das amostra de feijão da área não endêmica, foi de $25-27 \mu \mathrm{g} / \mathrm{kg}$ e na área endêmica, $25-50 \mu \mathrm{g} / \mathrm{kg} \mathrm{em} 16,7 \%$ das amostras de feijão. Para o milho, na área endêmica, $27,3 \%$ das amostras mostraram uma contaminação na faixa de $25-35 \mu \mathrm{g} / \mathrm{kg}$ e na área não endêmica, $9,0 \%$ da amostras mostraram uma contaminação na faixa de $10-25 \mu \mathrm{g} / \mathrm{kg}$.

Segundo HALD (1989) a ocratoxina A tem sido detectada em uma grande quantidade de alimentos e produtos, na maioria das vezes em paises com clima temperado e continental, apesar de também ter sido detectada em regiōes de clima quente. $A$ incidência da ocratoxina $A$, em grãos utilizados como alimentos, é baixa e os niveis são, na maioria das vezes, menor que 500 $\mu \mathrm{g} / \mathrm{kg}$. 
No Brasil são poucos os relatos de contaminação natural de produtos por ocratoxina $A$.

Em 1981 e 1982, FONSECA et al. (1982 e 1983) fizeram o primeiro levantamento da ocorrência de ocratoxina A em milho. Nestes estudos a ocratoxina A não foi detectada em nenhuma das 128 amostras de milho retiradas de prateleiras dos supermercados em algumas regiōes do Estado de São Paulo.

O trabalho de SOARES \& RODRIGUES-AMAYA (1989) foi o primeiro relato de ocorrência de ocratoxina $A$, no Brasil. Neste estudo $32 \mu \mathrm{g} / \mathrm{kg}$ de ocratoxina $A$ foi encontrada em uma amostra de milho branco retirada do varejo da região de Campinas, SP.

Apesar da quase inexistência de dados da ocorrência de ocratoxina $A$ em milho no Brasil, deve-se atentar para a possibilidade de que, certas situaçōes particulares de temperatura, umidade e micoflora, possiveis de ocorrerem nas diversas regiōes produtoras de milho a nível nacional, podem favorecer as espécies de fungos produtoras e, conseqüentemente, a produção da ocratoxina $A$.

No Brasil não existe limite legal para a presença de ocratoxina $A$ em alimentos e raçöes animais. 


\section{MATERIAL E MÉTODOS}

\subsection{Material}

O material utilizado nas análises, constituiu-se de 292 amostras de grãos de milho retiradas de cargas que chegavam à indústria alimentícia, em caminhões ou vagões ferroviários provenientes de diversos locais.

As amostras compostas, conforme definidas no item 4.2.1., eram então transportadas para o laboratório de micotoxinas do Departamento de Ciência e Tecnologia Agroindustrial, da Escola Superior de Agricultura Luiz de Queiroz, no prazo de até 12 horas a partir da coleta. As amostras compostas, que apresentavam teor de umidade igual ou acima de $14 \%$, eram armazenadas a $0^{\circ} \mathrm{C}$ até o momento de serem processadas.

\subsection{Metodologia}

\subsubsection{Método de Amostragem}

O levantamento foi realizado através de três amostragens, que foram realizadas em três dias. Os dias escolhidos para amostragem estavam distribuídos em épocas diferentes, dentro do prazo de um ano, de modo que coletou-se amostras de milho com históricos diferentes e portanto, abrangendo as variações da contaminação do milho que possam ter ocorrido, devido por exemplo, ao tempo de armazenamento, origem do milho, época de produção, 
etc. Assim, a primeira, segunda e terceira amostragens foram realizadas em outubro de 1993, março de 1994 e agosto de 1994, respectivamente.

Em cada amostragem, aproximadamente 100 carregamentos sequenciais de milho que chegavam à indústria dentro do dia escolhido para amostragem foram amostrados. Ao final do levantamento obteve-se um total de 292 amostras analisadas, sendo 96,106 e 91 amostras, analisadas no $1^{\circ}, 2^{\circ} \mathrm{e}$ $3^{\circ}$ período de amostragem respectivamente.

As amostragens foram realizadas seguindo o critério de se coletar amostras denominadas simples, retiradas em vários pontos da carga de milho, sendo um número maior de pontos amostrados quanto maior fosse a carga. Estas amostras simples, eram reunidas para compor uma amostra denominada composta a qual continha não menos que $5 \mathrm{~kg}$ de grãos. Esta amostra composta foi considerada como sendo representativa de cada carregamento amostrado que chegou à indústria.

Para cada amostra composta coletada, após a correta identificação com um número, foi anotada a origem do milho, a fim de se conhecer as regiōes de origem dos carregamentos; registrada a umidade média da carga, determinada pelo laboratório de controle de qualidade da indústria, através de um determinador de umidade de condução elétrica.

\subsubsection{Preparo das amostras}

Em uma primeira etapa do processamento, as amostras foram reduzidas do seu peso inicial de aproximadamente $5 \mathrm{~kg}$ para cerca de $1 \mathrm{~kg}$, obtendo-se uma amostra denominada amostra trabalho. A redução da amostra foi realizada através de um redutor de amostras recomendado para análise de sementes por (BRASIL,1980).

A segunda etapa do processamento da amostra envolveu a trituração e moagem dos grãos da amostra trabalho, até a obtenção de um 
material moído que passou em uma peneira de malha 20 "mesh". A amostra trabalho assim moida foi então novamente armazenada sob refrigeração a $0^{\circ} \mathrm{C}$, até o momento da análise.

No momento da análise, cada amostra foi bem homogeneizada manualmente e, então, retirou-se uma amostra analítica de $50 \mathrm{~g}$.

\subsubsection{Medologia analítica}

4.2.3.1. Placas cromatográficas, padrões e sistema de solventes.

Em virtude da metodologia adotada e das características dos extratos de milho, utilizou-se :

a) Placas de vidro, cobertas com uma camada de sílicagel G 60 (Merck art.7731) de espessura $0,3 \mathrm{~mm}$, ativadas por 1 hora a $110^{\circ} \mathrm{C}$ em estufa de circulação de ar.

b) Cromatofolhas de alumínio para cromatografia em camada delgada (CCD) com espessura da camada de silicagel de $0,2 \mathrm{~mm}$, para melhor visualiação de alguns extratos.

c) Padrões das aflatoxinas $B_{1}, B_{2}, G_{1}$ e $G_{2}$, zearalenona e ocratoxina $A$, na forma cristalina adquiridos de empresas especializadas, para preparo das soluções trabalho de cada micotoxina.

d) Solução padrão de trabalho de aflatoxinas $B_{1}, B_{2}, G_{1}$ e $G_{2}$, na concentração aproximada de $0,2 \mu \mathrm{g} / \mathrm{ml}$ cada, em benzeno + acetonitrilo $(98+2)$.

e) Solução padrão de trabalho de ocratoxina $A$ na concentração aproximada de $1-5 \mu \mathrm{g} / \mathrm{ml}$, em benzeno + ácido acético $(85+15)$.

f) Solução padrão de trabalho de zearalenona na concentração aproximada de $70 \mu \mathrm{g} / \mathrm{ml}$, em benzeno. 
A preparação de soluções estoque e a determinação exata das concentrações seguiu a metodologia descrita na "Association of the Official Analytical Chemists" (SCOTT, 1990), item 971.22.

g) Sistemas de solventes para desenvolvimento em CCD.

Tolueno - Acetato de etila - Ácido fórmico $(5+4+1)$

Clorofórmio - Acetona (9+1)

Benzeno - Metanol - Ácido acético $(9+0,5+0,5)$

\subsubsection{Extração e Clarificação da Amostra.}

A extração e a clarificação do extrato seguiu a metodologia desenvolvida por SOARES \& RODRIGUES AMAYA (1989), para análise simultânea das aflatoxinas $B_{1}, B_{2}, G_{1} \in G_{2}$, zearalenona, esterigmatocistina e ocratoxina A. A extração foi realizada conforme esquema a seguir:

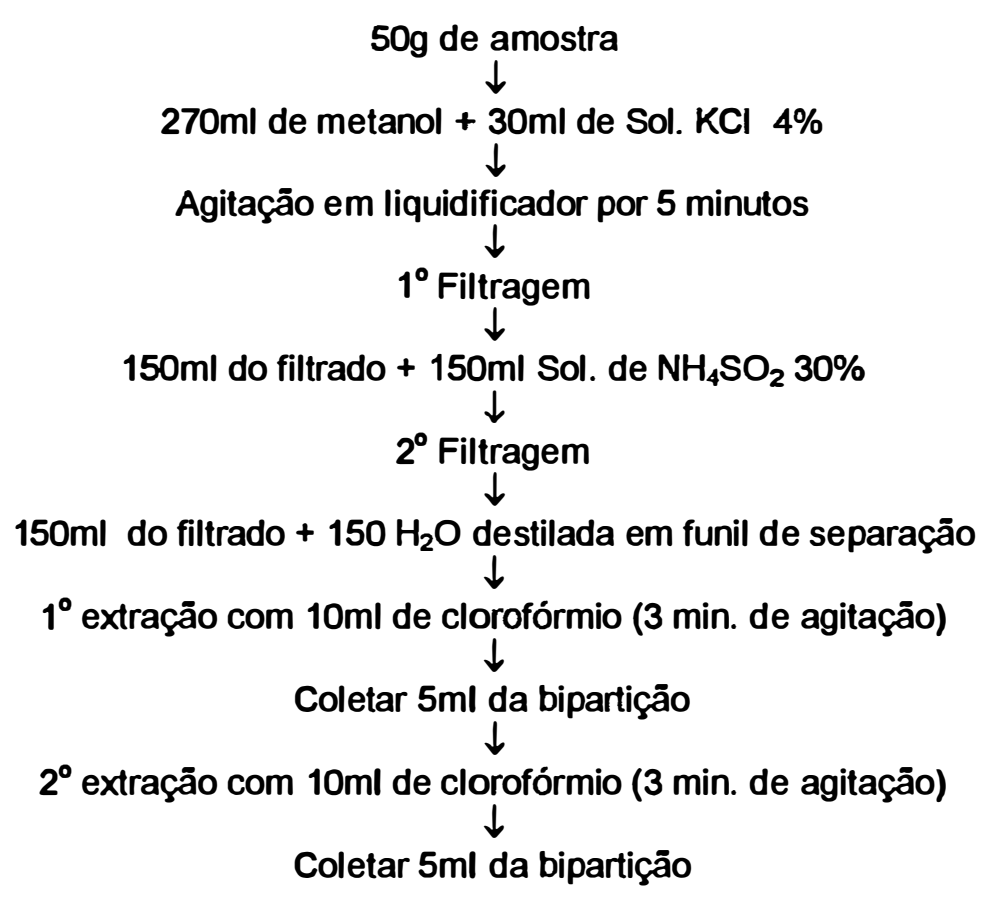




\subsubsection{Triagem.}

Em um frasco âmbar de volume aproximado de $15 \mathrm{ml}$ foram reunidas as duas alíquotas de $5 \mathrm{ml}$ provenientes da primeira e segunda partição com clorofórmio. Este volume foi evaporado até a secura em banhomaria, em até $80^{\circ} \mathrm{C}$, sob fluxo de nitrogênio, e em seguida redissolvido com $200 \mu \mathrm{l}$ de benzeno/acetonitrila $(98+2)$, tomando-se o cuidado de agitar 0 frasco, em agitador de tubos, por 30 s, para promover uma melhor redissolução.

A triagem foi realizada por CCD bidirecional. A escolha da cromatografia bidirecional foi devido, à constatação de que, ela trouxe uma melhor visualização das micotoxinas no extrato, como conseqüência da eliminação do chamado "cometa" amarelo, que dificultava muito a visualização da região onde param as mesmas. PATTERSON \& ROBERTS (1979), também optaram por está técnica, quando encontraram muitos interferentes em análise de rações.

O esquema da placa bidirecional está ilustrado na Figura 1. $\mathrm{Na}$ posição A, da placa, foi aplicado $10 \mu l$ da amostra. Na posição $B 3 \mu l$ do padrão, e nas posições $C, D$ e E foram aplicados 3, 4 e $6 \mu \mathrm{l}$, respectivamente, do padrão das aflatoxinas, quando estas foram investigadas. Quando a zearalenona ou ocratoxina A foram investigadas foram aplicados na posição $B 5 \mu \mathrm{l}$, e nas posiçōes $C$, D e E 1,3 e 5 $\mu$ l respectivamente, dos padrões de cada micotoxina.

A metodologia de separação bidirecional empregada mostrou um limite de visualização para as aflatoxinas $B_{1}, B_{2}, G_{1}$ e $G_{2}$, de $0,5 \mu \mathrm{g} / \mathrm{kg}$. Para zearalenona o limite foi de $290 \mu \mathrm{g} / \mathrm{kg}$. e para ocratoxina $A$ foi de $5,0 \mu \mathrm{g} / \mathrm{kg}$.

Quando necessário, em função das concentrações das micotoxinas encontradas nos extratos, alíquotas do padrão e do extrado da amostra, diferentes das mencionadas, foram aplicadas em uma nova placa para melhor comparação das fluorescências. 
As micotoxinas foram analisadas individualmente, de forma que cada extrato foi cromatografado três vezes, sendo uma vez para cada micotoxina.

As placas foram desenvolvidas inicialmente na direção 1 (Figura 1), em um primeiro sistema de solvente, depois retiradas da cuba de desenvolvimento, deixadas secar, giradas em $90^{\circ} \mathrm{e}$, colocadas para desenvolver na direção $2 \mathrm{em}$ um segundo sistema de solvente.

Os sistemas de solventes utilizados para desenvolvimento das placas na primeira e segunda direção, para as micotoxinas foram:

\begin{tabular}{|c|c|c|}
\hline Toxina & $1^{a}$ direção & $2^{\mathbf{a}}$ direção \\
\hline $\begin{array}{l}\text { Aflatoxinas } \\
\text { Zearalenona }\end{array}$ & $\begin{array}{c}\text { Benzeno-Metanol-Åc. acético } \\
(9-0,5-0,5) \\
\text { Clorofórmio-Acetona } \\
(9+1)\end{array}$ & $\begin{array}{l}\text { Tolueno+Acet. de Etila+Ác. Fórmico } \\
(6+4+1) \\
\text { Tolueno-Acet. de Etila-Ác. Fórmico } \\
(5+4+1)\end{array}$ \\
\hline Ocratoxina A & $\begin{array}{l}\text { Clorofórmio-Acetona } \\
(9+1)\end{array}$ & $\begin{array}{l}\text { Tolueno-Acet. de Etila-Ác. Fórmico } \\
\qquad(5+4+1)\end{array}$ \\
\hline
\end{tabular}

A visualização das micotoxinas foi feita sob luz ultravioleta de ondas longas $(366 \mathrm{~nm})$, para as aflatoxinas e ocratoxina $A$, e sob luz ultravioleta de ondas curtas $(254 \mathrm{~nm})$, para a zearalenona.

Quando houve suspeita de uma mancha poder ser a micotoxina zearalenona, a placa foi pulverizada com uma solução de cloreto de aluminio $20 \%$ e colocada em estufa por 5 minutos a $130^{\circ} \mathrm{C}$, objetivando facilitar a visualização da zearalenona.

Toda mancha fluorescente que apresentava a mesma tonalidade e localização concordante com a posição dos padrões das micotoxinas, após desenvolvimento das placas no primeiro e segundo sistema de solventes, foi considerada uma mancha positiva presuntiva para a micotoxina em questão, e então sua identidade foi testada. 


\subsubsection{Quantificação.}

A quantificação das amostras suspeitas foi feita na mesma placa de triagem, através da comparação visual da intensidade de fluorescência da mancha suspeita com a fluorescência das manchas das alíquotas dos padrões, aplicados nas posições C, D e E (Figura 1).

Quando houve necessidade, para um extrato específico, uma nova placa foi utilizada aplicando-se então uma alíquota da diluição do extrato da amostra ou alíquotas do padrão de micotoxinas, com volume diferente dos inicialmente utilizados. $O$ objetivo foi obter uma melhor aproximação da intensidade da fluorescência entre a mancha suspeita e o padrão.

Após a correta comparação, o cálculo da concentração da micotoxina foi efetuado aplicando-se a seguinte fórmula.

$$
\frac{Y \times S \times V}{X \times W}=\mu g / k g \text { de toxina ou ppb }
$$

onde:

$Y=$ concentração do padrão $\mathrm{em} \mu \mathrm{g} / \mathrm{ml}$

$\mathbf{S}=$ microlitros do padrão da toxina com fluorescência equivalente à do padrão

$V=$ Volume final, em $\mu l$, do extrato da amostra $(200 \mu l)$

$X=$ microlitros aplicados do extrato final $(10 \mu \mathrm{l})$

$W=$ peso da amostra, em gramas, no extrato final $(6,25 \mathrm{~g})$ 


\subsubsection{Confirmação}

A confirmação das manchas suspeitas para cada micotoxina, foi realizada inicialmente através da co-cromatografia do extrato com o padrão da micotoxina.

Com esse objetivo, uma nova placa foi utilizada. Nesta placa, esquematizada do mesmo modo que a primeira (Figura 1), na posicão $A$, após à aplicação dos $10 \mu l$ do extrato da amostra, foram aplicados $3 \mu$ do padrão da micotoxina a ser confirmada, e em cada uma das posições B e C foram aplicados $3 \mu l$ do padrão da mesma micotoxina.

Após o desenvolvimento da placa, nos sistemas de solventes adequados para cada micotoxina, conforme item 4.2.3.3., a cromatografia dos extratos, com e sem padrão, foram comparadas para observação da disposição da mancha suspeita, na primeira placa e, a disposição da micotoxina, na placa com padrão adicionado junto com a amostra. Quando houve a coincidência das posições, a mancha continuou sendo considerada positiva presuntiva. De outro modo, quando não houve coincidência o extrato foi considerado negativo para presença da micotoxina em questão.

A mancha ainda positiva presuntiva após a co-cromatografia foi testada definitivamente para confirmação, através da derivação química.

Para confirmação das aflatoxinas $B_{1}$ e $G_{1}$, por derivação química, foi utilizada a metodologia de (SCOTT, 1990), ítem 985.17 e para ocratoxina A e zearalenona, se fosse necessário, seria utilizada a metodologia de GOLINSKI \& GRABARKIEWICZ-SZCZENA (1984), respectivamente. 


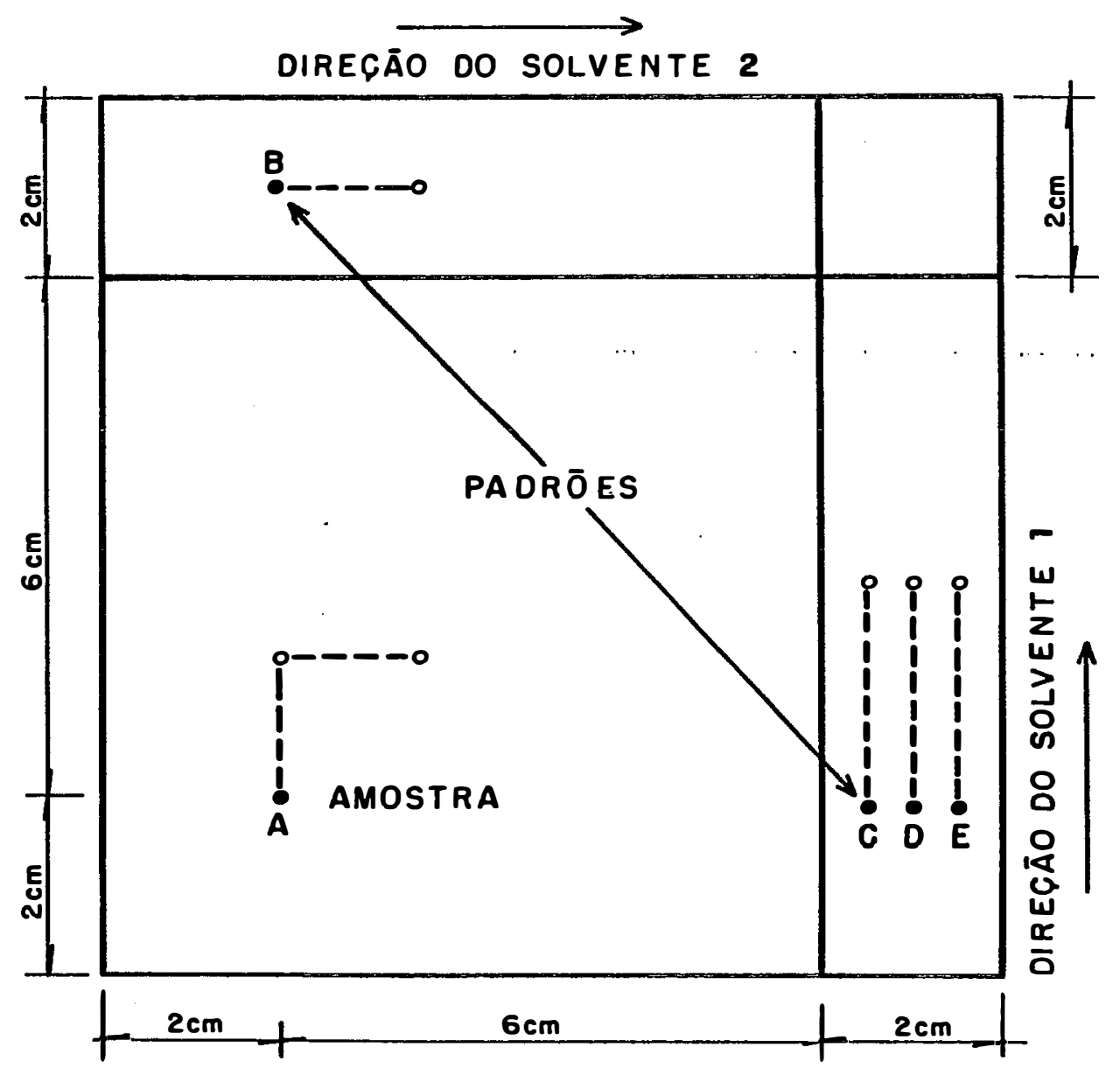

Figura 1 - Esquema da divisão da placa cromatográfica e disposição das aliquotas do padrão e extrato da amostra . 


\section{RESULTADOS E DISCUSSÃO}

\subsection{Aflatoxinas}

Os resultados das análises de micotoxinas são apresentados nas Tabelas 1, 2 e 3, para as $1^{a}, 2^{a}$ e $3^{a}$ amostragens, respectivamente, bem como um resumo do número total de amostras contaminadas por cada micotoxina, o valor médio e a amplitude da contaminação encontrada em cada periodo amostrado.

Na Tabela 4 é mostrado o número de amostras que chegaram à indústria com umidade igual ou acima de $14,5 \%$ e, também igual ou acima de $16 \%$.

Na Tabela 5 é mostrada a contaminação média e o valor máximo de contaminação encontrado em cada amostragem, considerando-se a soma das aflatoxinas $B_{1}+G_{1}$.

A distribuição das amostras, segundo a origem, assim como o número de amostras contaminadas em cada Estado e a percentagem destas em relação ao total de amostras do Estado são mostrados na Tabela 6.

Observa-se, através das Tabelas 1, 2, 3 e 6, que a procedência (Estado e município) das cargas de milho, variaram bastante entre as amostragens, mostrando que a origem do milho consumido depende da época do ano. Na primeira amostragem (outubro/1993) $100 \%$ das cargas eram provenientes de outros Estados e não de São Paulo enquanto que, na segunda 
(março/1994) e terceira amostragens (agosto/1994), 31,1\% e $76,6 \%$ dos carregamentos respectivamente eram provenientes de outros Estados.

Os registros mostram que o milho consumido pela indústria proveio de 17 municípios do Estado São Paulo, 1 de Minas Gerais, 3 de Mato Grosso, 4 de Mato Grosso do Sul, 5 de Góias e 7 do Paraná.

Estes dados vêm reforçar a constatação que São Paulo é um grande importador de milho de outros Estados do país, conforme afirmou COGO (1992).

Nos estudos da qualidade do milho em São Paulo é, pois, importante considerar-se as características do fluxo de fornecimento do milho ao mercado paulista, durante as épocas do ano.

A variação observada, quanto aos locais de origem do milho consumido, é um indicativo do potencial de contaminação com aflatoxina uma vez que, diferentes situações naturais, tecnológicas e sócio econômicas podem existir nas regiões produtoras de milho que, de acordo com MONTEIRO et al. (1992) podem ser classificadas em 92 zonas macroecológicas no Brasil.

Assim, considerar-se somente o milho produzido no local (Estado ou município) ou coletar o milho somente em um certo período do ano, pode induzir a erros de interpretação sobre a contaminação, com aflatoxinas, do milho aqui consumido.

As Tabelas 1, 2 e 3 mostram que, a contaminação do milho, com aflatoxinas, ocorreu nos três períodos de amostragem, apesar desta contaminação variar entre as amostragens, quanto ao número de amostras contaminadas e aos niveis de contaminação encontrados.

$A$ aflatoxina $B_{1}$ ocorreu em um maior número de amostras. Os indices de contaminação encontrados foram de $57,3 \%, 16 \%$ e de $27,7 \%$ para $1^{\mathrm{a}}, 2^{\mathrm{a}}$ e $3^{\mathrm{a}}$ amostragens (outubro/93, março/94 e agosto/94).

A contaminação das amostras pelas aflatoxinas $B_{2}, G_{1}$ e $G_{2}$, mostrado nas Tabela 1, 2 e 3, não alcançou niveis elevados, com exceção de 
apenas uma amostra que apresentou $85 \mu \mathrm{g} / \mathrm{kg}$ de aflatoxina $G_{1}$, na segunda amostragem, fazendo com que a contaminação média, nesta amostragem, fosse de $30,6 \mu \mathrm{g} / \mathrm{kg}$ para a aflatoxina $G_{1}$. $O$ número de amostras positivas para a presença destas aflatoxinas não chegou a ser tão alto como para a aflatoxina $B_{1}$, mas ocorreu em um número relativamente maior de amostras quando comparado com outros levantamentos realizados no Estado de São Paulo (FONSECA et al., 1983 e SCUSSEL et. al., 1986)

Os niveis médios de contaminação encontrados, considerandose a somatória das aflatoxinas $B_{1}$ e $G_{1}$ nas três amostragens, não foram altos (Tabela 5), apesar de existirem valores isolados de contaminação, entre a primeira e a segunda amostragem, bem acima do nivel máximo permitido pela legislação brasileira, que é de $30 \mu \mathrm{g} / \mathrm{kg}$, somando as aflatoxinas $B_{1}+G_{1}$ (BRASIL, 1977).

Ao final deste levantamento observou-se que, 7 amostras excederam o limite máximo de contaminação permitido, sendo que 2 amostras alcançaram uma contaminação acima de $100 \mu \mathrm{g} / \mathrm{kg}$ de $B_{1}+G_{1}$. Apesar da amostra com maior contaminação, $143 \mu \mathrm{g} / \mathrm{kg}$ de $B_{1}+G_{1}$, ter ocorrido na segunda amostragem, (Tabela 5), foi na primeira amostragem que ocorreram niveis médios de contaminação de $B_{1}+G_{1}$ mais altos.

Nenhum dos estudos de levantamento da ocorrência de aflatoxinas no milho no Estado de São Paulo apresentaram, até agora, um número de amostras contaminadas tão alto, quanto o encontrado neste levantamento. FONSECA et al. (1983), encontraram somente $4,7 \%$ das amostras de milho, retiradas de oito regiōes de São Paulo, contaminadas com aflatoxina $B_{1}$ e com níveis máximos de contaminação variando de 41$2.000 \mu \mathrm{g} / \mathrm{kg}$. SCUSSEL et al. (1986) também, encontraram somente duas amostras contaminadas dentre 83 amostras de milho e seus produtos retiradas 
da região de Campinas, SP. Os conteúdos de aflatoxina encontrados foram de 14 e $18 \mu \mathrm{g} / \mathrm{kg}$.

A contaminação do milho por aflatoxinas, mesmo em niveis baixos, é importante já que pode haver concentração através do processamento dos niveis destas em sub-produtos a serem utilizados para alimentação animal conforme (YAHL et al., 1971 e BENNETT \& ANDERSON, 1978) demonstraram para o processamento do milho a úmido. $A$ ingestão de raçōes contaminadas pelos animais pode resultar em perdas econômicas para os produtores e também, contaminar tecidos animais que servem de alimento para o homem, podendo provocar micotoxicoses de origem secundária, conforme afirmaram SMITH \& MOSS (1985).

$O$ indice de contaminação pelas aflatoxinas $B_{1}$ e $B_{2}$ em todas as amostragens, foi sempre maior que $o$ índice de contaminação pelas aflatoxinas $G_{1}$ e $G_{2}$. Isto pode indicar a predominância da contaminação do milho por fungos da espécie $A$. flavus (HESSELTINE et al., 1970 e DIENER et al., 1987).

Na Tabela 6 e na Figura 2, observa-se que as amostras do Estado do Paraná e Mato Grosso do Sul foram sistematicamente as mais contaminadas em cada amostragem. Nos carregamentos provenientes do Paraná, $85 \%, 34,7 \%, 43,5 \%$ e $56,1 \%$ das amostras, na primeira, segunda, terceira amostragens e no total de amostras do Estado, respectivamente, estavam contaminadas com aflatoxina $B_{1}$. Nas amostras provenientes do Mato Grosso do Sul os índices foram de $73 \%, 28,5 \%, 33 \%$ e $56,4 \%$. Com base nesta observação, é válido afirmar que, sistematicamente, o milho proveniente do Paraná e Mato Grosso do Sul, esteve à mercê de algum ou alguns fatores durante seu ciclo de produção ou posteriormente, que propiciaram a contaminação com aflatoxinas. Este fato sugere que os fornecedores de milho da indústria, localizados nos Estados do Paraná e Mato Grosso do Sul, devem ser melhor avaliados e as possiveis causas dessa contaminação detectadas, para que a qualidade possa melhorar. 
Fatores como períodos de seca, ataque de insetos e danos provocados por passáros, no decorrer do cultivo do milho no campo podem favorer a infecção dos grãos de milho por $A$. flavus ou $A$. parasiticus os quais, conseqüentemente, podem ter produzido as aflatoxinas durante esta fase ou em outra, como no pré-colheita, no transporte ou no armazenamento (BRADBURN et al., 1993).

Outra possibilidade seria a entrada do fungo pelo "cabelo", botanicamente definido como estilete e estigma do milho, o que pode provocar uma posterior contaminação dos grãos, se assim as condições de temperatura, disponibilidade de água e fungos coexistentes permitirem (JONES et al., 1980).

O transporte também é uma fase importante e dois pontos devem ser considerados, tais como, o reumedecimento dos grãos que viajaram sem uma adequada proteção, e grãos ainda com condições de umidade elevada. Pela observação das Tabelas 1, 2 e 3, notamos que, provavelmente, a segunda condição ocorreu em muitas das cargas de milho que chegaram à indústria. A Tabela 4 mostra que, na $1^{a}, 2^{a}$ e $3^{a}$ amostragens, $51 \%, 66,7 \%$ e $27,5 \%$ das amostras estavam com um nivel de umidade acima de $14,5 \%$, umidade esta considerada limite pelo Ministério da Agricultura (Portaria $n^{\circ} 845$ de novembro de 1976), para comercialização do milho. Acrescente-se a isto o fato que, nas duas primeiras amostragens, $26,3 \%$ e $57,5 \%$ das amostras apresentaram niveis acima de $16 \%$, considerado o limite máximo em condições de laboratório para que não ocorra produção de aflatoxinas no milho, segundo TRUCKSESS et al. (1988) e SAUER (1986).

Em alguns carregamentos, o tempo em que o milho permaneceu com niveis de umidade acima de $14,5 \%$, pode ter sido superior a dois dias, devido à distância entre alguns locais de produção e a indústria. Também, pode ter havido ainda algum tempo de espera na fila para descarregamento na indústria, devido ao limite da capacidade de recebimento de milho desta. 
O milho, quando mantido em equilibrio com uma umidade relativa elevada, pode apresentar-se contaminado por aflatoxinas dentro de $\mathbf{4 8}$ horas, de acordo com WINN \& LANE (1978) e THOMPSON et al. (1983).

Com a difusão e a utilização da colheita mecânica, em muitas propriedades, o milho é colhido com níveis de umidade entre $20 \%$ e $30 \%$, niveis estes mais adequados à colheiła mecânica. Muitos produtores, entretando, não secam o milho e transportam os grãos ainda com umidade elevada, deixando que o destinatário da carga realize a secagem dos grãos.

A colheita mecânica dos grãos é uma operação que pode favorecer a contaminação com aflatoxinas. Segundo TUITE et al. (1985), se o processo de colheita mecânica, não for bem conduzido, os grãos podem ter sua integridade danificada durante a colheita, facilitando a infecção, colonização e contaminação pelos fungos.

No entanto, a secagem do milho precisa ser também efetuada corretamente. TUITE \& FOSTER (1963), relatam que a secagem do milho em altas temperaturas pode aumentar a suscetibilidade do grão à invasão fúngica.

Muitos fatores podem favorecer a contaminação do milho armazenado. Dentre esses fatores, a temperatura e umidade são os mais fortes determinantes da contaminação ou não do milho durante o armazenamento.

BRADBURN et al. (1993), citando Ross et al. 19791, estimam que o milho pode ser armazenado com, no máximo, $13 \%$ de umidade por até um ano e com, no máximo, $11 \%$ por até cinco anos.

0 reumedecimento do milho armazenado pode ser um outro grande problema no pós-colheita. Isto pode ocorrer, por exemplo, devido a goteiras existentes no armazém, como resultado da atividade de insetos e também por correntes de convecção dentro dos silos.

\footnotetext{
1 ROSS, I. J.; LOWER, J.O;; WHITE, G.M. Potential for aflatoxin development in low temperature grain drying systems. American Society of Agricultural Engineers winter meeting. December 18-20, 1979. Palmer House, Chicago.
} 
Se o reumedecimento ocorrer, o problema da contaminação por aflatoxinas pode ser bastante sério. Segundo TRENK \& HARTMAN (1970), pode haver uma produção em niveis 10 vezes maiores, no milho reumedecido, que os encontrados no mesmo milho que não sofreu secagem e foi armazenado com níveis de umidade igualmente elevados.

\subsection{ZEARALENONA}

Os resultados das análises de zearalenona estão nas Tabelas 1 , 2 e 3. Nenhuma amostra de milho apresentou niveis detectáveis de contaminação por zearalenona.

Estudos anteriores realizados exclusivamente no Estado de São Paulo, também não encontraram zearalenona no milho (FONSECA et al.,1982 e 1983 e SOARES \& RODRIGUES-AMAYA, 1989).

SABINO et al. (1989) encontraram zearalenona em somente 7 amostras, dentre as 163 amostras de milho procedentes de São Paulo, Minas Gerais e Espírito Santo.

Segundo BALDISSERA et al. (1992) o Rio Grande do Sul é a região brasileira com maior risco de contaminação por zearalenona pois, neste Estado a temperatura é bastante baixa no inverno e a umidade ambiental é alta, favorecendo a formação desta micotoxina, durante o cultivo e, principalmente, durante no armazenamento dos grãos.

No presente levantamento, como pode ser observado nas Tabelas 1, 2 e 3, não houve carregamento de milho proveniente do Rio Grande do Sul. $O$ único Estado da região sul, que forneceu milho para à indústria foi o Paraná.
Uma provável causa da ausência de contaminação de zearalenona seria o fato do milho recebido pela indústria não ter sido 
submetido as condições de temperatura necessárias (KUIPER-GOODMAN et al., 1987), para a produção de zearalenona.

\subsection{OCRATOXINA A}

Os resultados das análises de ocratoxina $A$ são ilustrados nas Tabelas 1,2 e 3. Nenhuma amostra deste levantamento apresentou nivel detectável de ocratoxina $A$.

Estudos anteriores de FONSECA et al. (1982 e 1983) também não detectaram contaminação com ocratoxina $A$ no milho amostrado em oito regiōes do Estado de São Paulo. SOARES \& RODRIGUES-AMAYA (1989) analisando 130 amostras de milho e produtos a base de milho, coletados na região de Campinas, SP, encontraram somente uma amostra , contaminada com ocratoxina $A$.

Em muitas das cargas de milho pode ter havido condições de temperatura e umidade suficientes para crescimento de fungos e produção de ocratoxina A (NORTHOLT et al., 1979). Contudo, pelos resultados observados, outros fatores parecem estar atuando para inibir o aparecimento de ocratoxina A.

CHELACK et al (1991) mostraram que a presença de microbiota competitiva, em um substrato, afeta o $A$. allutaceus, provocando uma diminuição drástica dos niveis finais de ocratoxina $A$ encontrados.

Assim, é possivel que mesmo havendo condições de temperatura e umidade favoráveis à contaminação com ocratoxina $A$, outros fatores, como a presença de microbiota competitiva, podem ter reprimido a produção de ocratoxina $A$, mesmo se fungos produtores estiverem presentes nos grãos. 


\section{CONCLUSÕES}

a) A aflatoxina $B_{1}$ foi a aflatoxina que mais ocorreu, sendo detectada em 98 (33,5\%) do total das 292 amostras analisadas.

b) A contaminação média encontrada para a soma das aflatoxinas $B_{1}+G_{1}$, foi de $14,9 \mu \mathrm{g} / \mathrm{kg}, 13,9 \mu \mathrm{g} / \mathrm{kg}$ e $4,3 \mu \mathrm{g} / \mathrm{kg}$ para primeira, segunda e terceira amostragens, respectivamente. Apenas 7 amostras excederam o limite tolerado pela legislação brasileira, que é de $30 \mu \mathrm{g} / \mathrm{kg}$.

c) As micotoxinas zearalenona e ocratoxina $A$, não foram detectadas.

d) $O$ indice de contaminação do milho com aflatoxinas variou bastante entre os periodos de amostragem, tendo sido mais elevado na primeira amostragem (outubro/1993).

e) 0 milho proveniente dos Estados do Paraná e Mato Grosso do Sul, apresentou-se relativamente mais contaminado, por aflatoxinas, do que o milho proveniente de outros Estados.

f) 0 nivel de umidade de $51 \%, 66,9 \%$ e $27 \%$ do milho dos carregamentos na primeira, segunda e terceira amostragens, respectivamente, excederam o valor de $14,5 \%$, teor de umidade recomendado como máximo para comercialização do milho pelo Ministério da Agricultura do Brasil.

g) $O$ milho fornecido para indústria proveio de diferentes Estados durante os períodos do ano, sendo fornecedores 5 Estados além de São Paulo. 
h) Amostras de milho devem ser analisadas em diversas épocas do ano, para uma melhor avaliação de sua qualidade quanto a presença de micotoxinas. 


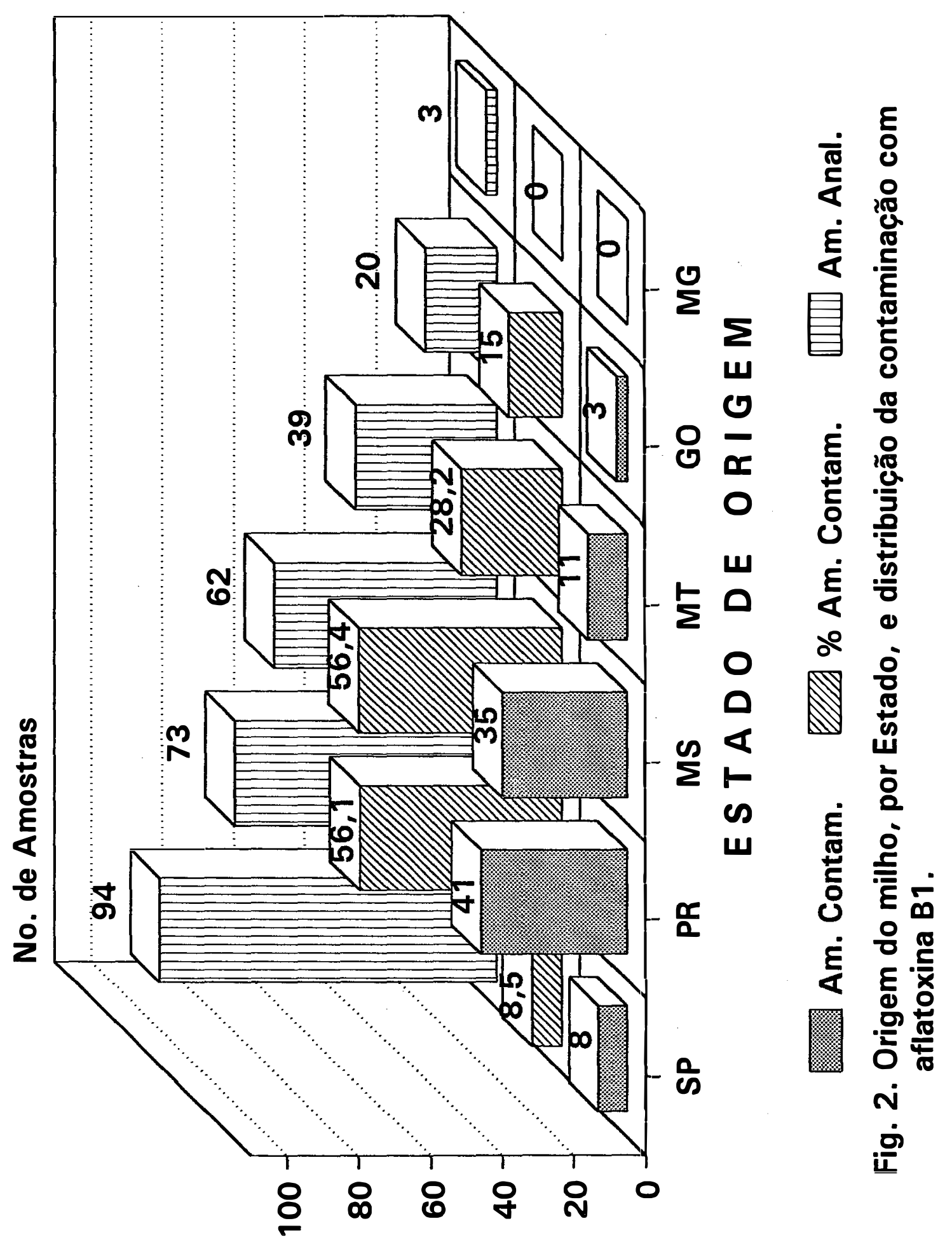


Tabela 1 - Procedência, umidade de entrada na indústria e resultados da contaminação com micotoxinas, dos 96 carregamentos amostrados em outubro de 1993.

\begin{tabular}{|c|c|c|c|c|c|c|c|c|}
\hline Procedência & U.F. & Umidade $\%$ & $\begin{array}{c}\text { AFLA. } \\
B_{1}\end{array}$ & $\begin{array}{l}\text { AFLA. } \\
\begin{array}{c}\mathrm{B}_{2} \\
\mu g\end{array}\end{array}$ & $\begin{array}{l}\text { AFLA. } \\
G_{1} \\
\text { kg }\end{array}$ & $\begin{array}{c}\overline{A F L A} . \\
G_{2}\end{array}$ & $\begin{array}{l}\text { OCRATOXINA A } \\
\text { pglkg }\end{array}$ & $\begin{array}{c}\text { ZEARALENONA } \\
\mu g / k g\end{array}$ \\
\hline Rio Brilhante & MS & 12.4 & 2 & 2 & 2 & 2 & N.D. & N.D. \\
\hline Rondonópolis & MT & 12.6 & 7 & N.D. & N.D. & N.D. & N.D. & N.D. \\
\hline Jataí & GO & 12.6 & N.D. & N.D. & N.D. & N.D. & N.D. & N.D. \\
\hline Goiânia & GO & 12.7 & N.D. & N.D. & N.D. & N.D. & N.D. & N.D. \\
\hline Rondonópolis & MT & 12.7 & N.D. & N.D. & N.D. & N.D. & N.D. & N.D. \\
\hline Jataí & GO & 12.8 & N.D. & N.D. & N.D. & N.D. & N.D. & N.D. \\
\hline Goiânia & GO & 12.8 & N.D. & N.D. & N.D. & N.D. & N.D. & N.D. \\
\hline Rondonópolis & MT & 13.0 & N.D. & N.D. & N.D. & N.D. & N.D. & N.D. \\
\hline Goiånia & GO & 13.0 & N.D. & N.D. & N.D. & N.D. & N.D. & N.D. \\
\hline Jataí & GO & 13.1 & N.D. & N.D. & N.D. & N.D. & N.D. & N.D. \\
\hline Rondonópolis & MT & 13.1 & N.D. & N.D. & N.D. & N.D. & N.D. & N.D. \\
\hline Rondonópolis & MT & 13.1 & N.D. & N.D. & N.D. & N.D. & N.D. & N.D. \\
\hline Campo Grande & M.S & 13.1 & N.D. & N.D. & N.D. & N.D. & N.D. & N.D. \\
\hline Jataí & GO & 13.2 & N.D. & N.D. & N.D. & N.D. & N.D. & N.D. \\
\hline Rondonópolis & MT & 13.2 & N.D. & N.D. & N.D. & N.D. & N.D. & N.D. \\
\hline Caarapó & MS & 13.3 & 16 & 2 & N.D. & N.D. & N.D. & N.D. \\
\hline Rondonópolis & MT & 13.3 & N.D. & N.D. & N.D. & N.D. & N.D. & N.D. \\
\hline Jataí & GO & 13.3 & N.D. & N.D. & N.D. & N.D. & N.D. & N.D. \\
\hline Rondonópolis & MT & 13.3 & N.D. & N.D. & N.D. & N.D. & N.D. & N.D. \\
\hline Caarapó & MS & 13.4 & 2 & N.D. & N.D. & N.D. & N.D. & N.D. \\
\hline Rondonópolis & MT & 13.4 & N.D. & N.D. & N.D. & N.D. & N.D. & N.D. \\
\hline Campo Grande & M.S & 13.5 & 2 & N.D. & N.D. & N.D. & N.D. & N.D. \\
\hline Caarapó & MS & 13.5 & N.D. & N.D. & N.D. & N.D. & N.D. & N.D. \\
\hline Rondonópolis & MT & 13.5 & N.D. & N.D. & N.D. & N.D. & N.D. & N.D. \\
\hline Rondonópolis & MT & 13.7 & 27 & 3 & 5 & 1 & N.D. & N.D. \\
\hline Caarapó & MS & 13.8 & 7 & N.D. & N.D. & N.D. & N.D. & N.D. \\
\hline Rio Brilhante & MS & 13.8 & N.D. & N.D. & N.D. & N.D. & N.D. & N.D. \\
\hline Rondonópolis & MT & 13.8 & N.D. & N.D. & N.D. & N.D. & N.D. & N.D. \\
\hline
\end{tabular}


Continuação da Tabela 1.

\begin{tabular}{|c|c|c|c|c|c|c|c|c|}
\hline Procedéncia & U.F. & Umidade \% & $\begin{array}{c}\text { AFLA. } \\
B_{1}\end{array}$ & $\begin{array}{c}\text { AFLA. } \\
B_{2} \\
\mu 0\end{array}$ & $\begin{array}{l}\text { AFLA. } \\
G_{1}\end{array}$ & $\begin{array}{c}\text { AFLA. } \\
G_{2}\end{array}$ & $\begin{array}{c}\text { OCRATOXINA A } \\
\mu g / k g\end{array}$ & $\begin{array}{c}\text { ZEARALENONA } \\
\mu g / k g\end{array}$ \\
\hline Rondonopolis & MT & 13.8 & N.D. & N.D. & N.D. & N.D. & N.D. & N.D. \\
\hline Rondonopolis & MT & 13.8 & N.D. & N.D. & N.D. & N.D. & N.D. & N.D. \\
\hline Rondonópolis & MT & 13.9 & 2 & N.D. & N.D. & N.D. & N.D. & N.D. \\
\hline Rondonopolis & MT & 13.9 & N.D. & N.D. & N.D. & N.D. & N.D. & N.D. \\
\hline Rondonopolis & MT & 13.9 & N.D. & N.D. & N.D. & N.D. & N.D. & N.D. \\
\hline Rio Brilhante & MS & 13.9 & N.D. & N.D. & N.D. & N.D. & N.D. & N.D. \\
\hline Rondonopolis & MT & 14.0 & 2 & N.D. & N.D. & N.D. & N.D. & N.D. \\
\hline Campo Grande & MS & 14.0 & 22 & 9 & N.D. & N.D. & N.D. & N.D. \\
\hline Rondon6polis & MT & 14.0 & N.D. & N.D. & N.D. & N.D. & N.D. & N.D. \\
\hline Rio Brilhante & MS & 14.0 & N.D. & N.D. & N.D. & N.D. & N.D. & N.D. \\
\hline Campo Grande & MS & 14.1 & 8 & 2 & N.D. & N.D. & N.D. & N.D. \\
\hline Rondonopolis & MT & 14.1 & N.D. & N.D. & N.D. & N.D. & N.D. & N.D. \\
\hline Rio Brilhante & MS & 14.1 & N.D. & N.D. & N.D. & N.D. & N.D. & N.D. \\
\hline Rondonopolis & MT & 14.2 & 2 & N.D. & N.D. & N.D. & N.D. & N.D. \\
\hline Campo Grande & MS & 14.2 & 27 & 2 & N.D. & N.D. & N.D. & N.D. \\
\hline Campo Grande & MS & 14.2 & N.D. & N.D. & N.D. & N.D. & N.D. & N.D. \\
\hline Campo Grande & MS & 14.3 & 2 & N.D. & N.D. & N.D. & N.D. & N.D. \\
\hline Jataí & GO & 14.4 & N.D. & N.D. & N.D. & N.D. & N.D. & N.D. \\
\hline Campo Grande & MS & 14.4 & 3 & 1 & N.D. & N.D. & N.D. & N.D. \\
\hline Campo Grande & MS & 14.6 & 4 & N.D. & N.D. & N.D. & N.D. & N.D. \\
\hline Campo Grande & MS & 14.6 & 11 & N.D. & N.D. & N.D. & N.D. & N.D. \\
\hline Campo Grande & MS & 14.7 & 9 & 2 & N.D. & N.D. & N.D. & N.D. \\
\hline Sertan6polis & PR & 14.7 & 9 & N.D. & N.D. & N.D. & N.D. & N.D. \\
\hline Campo Grande & MS & 14.8 & 2 & N.D. & N.D. & N.D. & N.D. & N.D. \\
\hline Rondonбpolis & MS & 14.8 & N.D. & N.D. & N.D. & N.D. & N.D. & N.D. \\
\hline Caarapo & MS & 15.0 & 2 & N.D. & N.D. & N.D. & N.D. & N.D. \\
\hline Campo Grande & MS & 15.0 & 7 & N.D. & N.D. & N.D. & N.D. & N.D. \\
\hline Campo Grande & MS & 15.0 & 7 & 2 & N.D. & N.D. & N.D. & N.D. \\
\hline Campo Grande & MS & 15.0 & 18 & 14 & N.D. & N.D. & N.D. & N.D. \\
\hline
\end{tabular}


Continuação da Tabela 1.

\begin{tabular}{|c|c|c|c|c|c|c|c|c|}
\hline Procedéncia & U.F. & Umidade $\%$ & $\begin{array}{c}\text { AFLA. } \\
B_{1}\end{array}$ & $\begin{array}{c}\text { AFLA. } \\
B_{2} \\
\mu g\end{array}$ & $\begin{array}{l}\text { AFLA. } \\
G_{1} \\
g\end{array}$ & $\begin{array}{c}\text { AFLA. } \\
G_{2}\end{array}$ & $\begin{array}{c}\text { OCRATOXINA A } \\
\text { pgikg }\end{array}$ & $\begin{array}{c}\text { 2EARALENONA } \\
\mu g l k g\end{array}$ \\
\hline Sertanópolis & PR & 15.1 & 9 & N.D. & N.D. & N.D. & N.D. & N.D. \\
\hline Campo Grande & MS & 15.1 & 9 & 2 & 7 & 1 & N.D. & N.D. \\
\hline Campo Grande & MS & 15.2 & 22 & 5 & N.D. & N.D. & N.D. & N.D. \\
\hline Sertanópolis & PR & 15.3 & 18 & 2 & N.D. & N.D. & N.D. & N.D. \\
\hline Rondonópolis & MT & 15.3 & N.D. & N.D. & N.D. & N.D. & N.D. & N.D. \\
\hline Rio Brilhante & MS & 15.3 & N.D. & N.D. & N.D. & N.D. & N.D. & N.D. \\
\hline Rio Brilhante & MS & 15.3 & N.D. & N.D. & N.D. & N.D. & N.D. & N.D. \\
\hline Caarapo & MS & 15.4 & 2 & 2 & 2 & 2 & N.D. & N.D. \\
\hline Campo Grande & MS & 15.4 & 11 & 2 & N.D. & N.D. & N.D. & N.D. \\
\hline Sertanópolis & PR & 15.5 & 11 & N.D. & N.D. & N.D. & N.D. & N.D. \\
\hline Caarapó & MS & 15.6 & 7 & N.D. & N.D. & N.D. & N.D. & N.D. \\
\hline Campo Grande & MS & 15.6 & 16 & 2 & N.D. & N.D. & N.D. & N.D. \\
\hline Campo Grande & MS & 15.8 & N.D. & N.D. & N.D. & N.D. & N.D. & N.D. \\
\hline Sertanópolis & PR & 15.9 & 7 & N.D. & N.D. & N.D. & N.D. & N.D. \\
\hline Sertanópolis & PR & 16.0 & 22 & 2 & N.D. & N.D. & N.D. & N.D. \\
\hline Sertanópolis & PR & 16.2 & 7 & N.D. & N.D. & N.D. & N.D. & N.D. \\
\hline Sertanópolis & $\overline{P R}$ & 16.3 & 2 & N.D. & N.D. & N.D. & N.D. & N.D. \\
\hline Sertanópolis & PR & 16.3 & 15 & N.D. & N.D. & N.D. & N.D. & N.D. \\
\hline Campo Grande & MS & 16.4 & 2 & N.D. & N.D. & N.D. & N.D. & N.D. \\
\hline Sertanópolis & PR & 16.5 & 2 & N.D. & N.D. & N.D. & N.D. & N.D. \\
\hline Sertanópolis & PR & 16.5 & N.D. & N.D. & N.D. & N.D. & N.D. & N.D. \\
\hline Sertanópolis & PR & 16.7 & 11 & 2 & N.D. & N.D. & N.D. & N.D. \\
\hline Sertanópolis & PR & 16.8 & N.D. & N.D. & N.D. & N.D. & N.D. & N.D. \\
\hline Campo Grande & MS & 17.1 & 2 & N.D. & N.D. & N.D. & N.D. & N.D. \\
\hline Santa Mariana & PR & 20.6 & N.D. & N.D. & N.D. & N.D. & N.D. & N.D. \\
\hline Santa Mariana & PR & 20.9 & 44 & 7 & 5 & 2 & N.D. & N.D. \\
\hline Santa Mariana & PR & 20.9 & 66 & 17 & 4 & N.D. & N.D. & N.D. \\
\hline Santa Mariana & PR & 21.3 & 44 & 9 & 2 & N.D. & N.D. & N.D. \\
\hline Santa Mariana & PR & 21.5 & 33 & 5 & 2 & N.D. & N.D. & N.D. \\
\hline Santa Mariana & PR & 21.5 & 89 & 17 & 18 & 4 & N.D. & N.D. \\
\hline
\end{tabular}


Continuação da Tabela 1

\begin{tabular}{|c|c|c|c|c|c|c|c|c|}
\hline Procedéncia & U.F. & Umidade $\%$ & $\begin{array}{l}\text { AFLA. } \\
B_{1}\end{array}$ & $\begin{array}{l}\text { AFLA. } \\
B_{2} \\
H g\end{array}$ & $\begin{array}{l}\text { AFLA } \\
\text { G, } \\
\text { Ithg }\end{array}$ & $\begin{array}{l}\text { AFLA. } \\
\mathbf{G}_{2}\end{array}$ & $\begin{array}{c}\text { OCRATOXINA A } \\
\mu g l k g\end{array}$ & $\begin{array}{c}\text { ZEARALENONA } \\
\mu g l k g\end{array}$ \\
\hline Santa Mariana & PR & 21.6 & 2 & N.D. & N.D. & N.D. & N.D. & N.D. \\
\hline Santa Mariana & PR & 22.0 & 55 & 17 & N.D. & N.D. & N.D. & N.D. \\
\hline Santa Mariana & PR & 22.4 & 22 & N.D. & N.D. & N.D. & N.D. & N.D. \\
\hline Santa Mariana & PR & 22.5 & N.D. & N.D. & N.D. & N.D. & N.D. & N.D. \\
\hline Santa Mariana & PR & 22.6 & 4 & N.D. & N.D. & N.D. & N.D. & N.D. \\
\hline Campo Grande & MS & 22.6 & 5 & N.D. & N.D. & N.D. & N.D. & N.D. \\
\hline Santa Mariana & PR & 23.1 & 2 & N.D. & N.D. & N.D. & N.D. & N.D. \\
\hline Santa Mariana & PR & 23.5 & 2 & N.D. & N.D. & N.D. & N.D. & N.D. \\
\hline Santa Mariana & PR & 24.0 & 22 & N.D. & 6 & N.D. & N.D. & N.D. \\
\hline $\begin{array}{c}\text { Contaminação } \\
\text { Média } \\
\mu \mathrm{g} / \mathrm{kg}\end{array}$ & & & 13,9 & 3,4 & 5,3 & 2,0 & 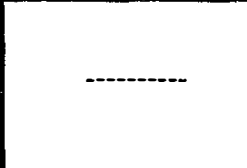 & ------ \\
\hline $\begin{array}{c}\text { Amostras } \\
\text { contaminadas }\end{array}$ & & & $\begin{array}{c}55 \\
(57,3 \%)\end{array}$ & $\begin{array}{c}24 \\
(25,0 \%)\end{array}$ & $\begin{array}{c}10 \\
(10,4 \%)\end{array}$ & $\begin{array}{c}6 \\
(6,2 \%)\end{array}$ & -........- & ------ \\
\hline $\begin{array}{c}\text { Amplitude de } \\
\text { variação } \\
\mu \mathrm{g} / \mathrm{kg}\end{array}$ & & & $2-89$ & $1-17$ & $2-18$ & $1-4$ & -----.---- & ----... \\
\hline
\end{tabular}

* Média de amostras contaminadas.

N.D. - Não detectada. 
Tabela 2 - Procedência, umidade de entrada na indústria e resultados da contaminação com micotoxinas, dos 106 carregamentos amostrados em outubro de 1993.

\begin{tabular}{|c|c|c|c|c|c|c|c|c|}
\hline Procedência & U.F. & Umidade $\%$ & $\begin{array}{c}\text { AFLA. } \\
\text { B, }\end{array}$ & $\begin{array}{c}\text { AFLA. } \\
\begin{array}{c}B_{2} \\
\text { pgl }\end{array}\end{array}$ & $\begin{array}{l}\text { AFLA } \\
\text { G, }\end{array}$ & $\begin{array}{c}\text { AFLA. } \\
G_{2}\end{array}$ & $\begin{array}{c}\text { OCRATOXINA A } \\
\text { rglkg }\end{array}$ & $\begin{array}{c}\text { ZEARALENONA } \\
\mu g l k g\end{array}$ \\
\hline Bandeirantes & PR & 12.4 & N.D. & N.D. & N.D. & N.D. & N.D. & N.D. \\
\hline Bandeirantes & PR & 12.4 & N.D. & N.D. & N.D. & N.D. & N.D. & N.D. \\
\hline Bandeirantes & PR & 12.5 & N.D. & N.D. & N.D. & N.D. & N.D. & N.D. \\
\hline São J. da Barra & SP & 12.5 & N.D. & N.D. & N.D. & N.D. & N.D. & N.D. \\
\hline Bandeirantes & PR & 12.6 & N.D. & N.D. & N.D. & N.D. & N.D. & N.D. \\
\hline São J. da Barra & SP & 12.7 & N.D. & N.D. & N.D. & N.D. & N.D. & N.D. \\
\hline Bandeirantes & PR & 12.7 & 6 & 1 & N.D. & N.D. & N.D. & N.D. \\
\hline São J. da Barra & SP & 12.7 & N.D. & N.D. & N.D. & N.D. & N.D. & N.D. \\
\hline São J. da Barra & SP & 12.9 & N.D. & N.D. & N.D. & N.D. & N.D. & N.D. \\
\hline São J. da Barra & SP & 12.9 & N.D. & N.D. & N.D. & N.D. & N.D. & N.D. \\
\hline Bandeirantes & PR & 13.0 & 3 & N.D & N.D. & N.D. & N.D. & N.D. \\
\hline Bandeirantes & PR & 13.0 & 5 & 1 & N.D. & N.D. & N.D. & N.D. \\
\hline São J. da Barra & SP & 13.0 & N.D. & N.D. & N.D. & N.D. & N.D. & N.D. \\
\hline São J. da Barra & SP & 13.0 & N.D. & N.D. & N.D. & N.D. & N.D. & N.D. \\
\hline São J. da Barra & SP & 13.2 & N.D. & N.D. & N.D. & N.D. & N.D. & N.D. \\
\hline Tamarana & PR & 13.2 & 9 & 2 & N.D. & N.D. & N.D. & N.D. \\
\hline Bandeirantes & GO & 13.2 & 3 & N.D. & N.D. & N.D. & N.D. & N.D. \\
\hline Bandeirantes & PR & 13.3 & N.D. & N.D. & N.D. & N.D. & N.D. & N.D. \\
\hline São J. da Barra & SP & 13.5 & N.D. & N.D. & N.D. & N.D. & N.D. & N.D. \\
\hline São J. da Barra & SP & 13.5 & N.D. & N.D. & N.D. & N.D. & N.D. & N.D. \\
\hline São J. da Barra & SP & 13.6 & N.D. & N.D. & N.D. & N.D. & N.D. & N.D. \\
\hline Bandeirantes & PR & 13.6 & N.D. & N.D. & N.D. & N.D. & N.D. & N.D. \\
\hline São J. da Barra & SP & 13.7 & N.D. & N.D. & N.D. & N.D. & N.D. & N.D. \\
\hline Chapadão do Sul & MS & 13.9 & N.D. & N.D. & N.D. & N.D. & N.D. & N.D. \\
\hline São J. da Barra & SP & 13.9 & N.D. & N.D. & N.D. & N.D. & N.D. & N.D. \\
\hline São J. da Barra & SP & 13.9 & N.D. & N.D. & N.D. & N.D. & N.D. & N.D. \\
\hline Chapadão do Sul & MS & 14.0 & N.D. & N.D. & N.D. & N.D. & N.D. & N.D. \\
\hline Palmeiras de Goias & GO & 14.0 & N.D. & N.D. & N.D. & N.D. & N.D. & N.D. \\
\hline
\end{tabular}


Continuação da Tabela 2.

\begin{tabular}{|c|c|c|c|c|c|c|c|c|}
\hline Procedéncia & U.F. & Umidade \% & $\begin{array}{l}\text { AFLA. } \\
\text { B, }\end{array}$ & $\begin{array}{c}\text { AFLA. } \\
B_{2} \\
\mu g l\end{array}$ & $\begin{array}{l}\text { AFLA } \\
G_{1}\end{array}$ & $\begin{array}{c}\text { AFLA. } \\
G_{2}\end{array}$ & $\begin{array}{c}\text { OCRATOXINA A } \\
\mu g / k g\end{array}$ & ZEARALENONA \\
\hline Chapadão do Sul & MS & 14.1 & N.D. & N.D. & N.D. & N.D. & N.D. & N.D. \\
\hline Sertanopólis & PR & 14.1 & 8 & N.D. & N.D. & N.D. & N.D. & N.D. \\
\hline Tamarana & PR & 14.1 & 3 & N.D. & N.D. & N.D. & N.D. & N.D. \\
\hline Tamarana & PR & 14.1 & N.D. & N.D. & N.D. & N.D. & N.D. & N.D. \\
\hline Chapadão do Sul & MS & 14.2 & 3 & N.D. & N.D. & N.D. & N.D. & N.D. \\
\hline Tamarana & PR & 14.2 & 3 & N.D. & N.D. & N.D. & N.D. & N.D. \\
\hline Tamarana & PR & 14.3 & N.D. & N.D. & N.D. & N.D. & N.D. & N.D. \\
\hline Tamarana & PR & 14.5 & N.D. & N.D. & N.D. & N.D. & N.D. & N.D. \\
\hline Tamarana & $\overline{P R}$ & 14.6 & N.D. & N.D. & N.D. & N.D. & N.D. & N.D. \\
\hline Tamarana & PR & 14.6 & N.D. & N.D. & N.D. & N.D. & N.D. & N.D. \\
\hline Tamarana & PR & 14.6 & N.D. & N.D. & N.D. & N.D. & N.D. & N.D. \\
\hline Tamarana & PR & 14.7 & N.D. & N.D. & N.D. & N.D. & N.D. & N.D. \\
\hline São J. da Barra & SP & 14.9 & N.D. & N.D. & N.D. & N.D. & N.D. & N.D. \\
\hline Palmeiras de Goias & GO & 15.2 & N.D. & N.D. & N.D. & N.D. & N.D. & N.D. \\
\hline Tamarana & PR & 15.4 & 5 & N.D. & 4 & N.D. & N.D. & N.D. \\
\hline Tamarana & PR & 15.5 & N.D. & N.D. & N.D. & N.D. & N.D. & N.D. \\
\hline Araras & SP & 15.6 & N.D. & N.D. & N.D. & N.D. & N.D. & N.D. \\
\hline Mogi Guaçu & SP & 16.1 & N.D. & N.D. & N.D. & N.D. & N.D. & N.D. \\
\hline Aguar & SP & 16.1 & N.D. & N.D. & N.D. & N.D. & N.D. & N.D. \\
\hline Mogi Guaçu & SP & 16.4 & N.D. & N.D. & N.D. & N.D. & N.D. & N.D. \\
\hline Tamarana & PR & 16.5 & N.D. & N.D. & N.D. & N.D. & N.D. & N.D. \\
\hline Mogi Guaçu & SP & 17.3 & N.D. & N.D. & N.D. & N.D. & N.D. & N.D. \\
\hline Artur Nogueira & SP & 17.4 & N.D. & N.D. & N.D. & N.D. & N.D. & N.D. \\
\hline Araras & SP & 17.8 & N.D. & N.D. & N.D. & N.D. & N.D. & N.D. \\
\hline Casa Branca & SP & 17.8 & N.D. & N.D. & N.D. & N.D. & N.D. & N.D. \\
\hline Aguaí & SP & 18.1 & N.D. & N.D. & N.D. & N.D. & N.D. & N.D. \\
\hline Pirassununga & $\mathrm{SP}$ & 18.5 & N.D. & N.D. & N.D. & N.D. & N.D. & N.D. \\
\hline Casa Branca & SP & 18.9 & N.D. & N.D. & N.D. & N.D. & N.D. & N.D. \\
\hline Leme & SP & 18.9 & 58 & 2 & 85 & 6 & N.D. & N.D. \\
\hline Araras & SP & 19.0 & N.D. & N.D. & N.D. & N.D. & N.D. & N.D. \\
\hline
\end{tabular}


Continuação da Tabela 2.

\begin{tabular}{|c|c|c|c|c|c|c|c|c|}
\hline Procedéncia & U.F. & Umidade $\%$ & $\begin{array}{l}\text { AFLA } \\
B_{1}\end{array}$ & $\begin{array}{l}\text { AFLA. } \\
B_{2} \\
\mu g / k\end{array}$ & $\begin{array}{l}\text { AFLA } \\
O_{1}\end{array}$ & $\begin{array}{c}\text { AFLA. } \\
G_{2} \\
\end{array}$ & $\begin{array}{c}\text { OCRATOXINA A } \\
\text { Hglkg }\end{array}$ & ZEARALENONA \\
\hline Araras & SP & 19.2 & N.D. & N.D. & N.D. & N.D. & N.D. & N.D. \\
\hline Aguar & SP & 19.2 & N.D. & N.D. & N.D. & N.D. & N.D. & N.D. \\
\hline Araras & SP & 19.2 & N.D. & N.D. & N.D. & N.D. & N.D. & N.D. \\
\hline Leme & SP & 19.3 & N.D. & N.D. & N.D. & N.D. & N.D. & N.D. \\
\hline Limeira & SP & 19.4 & 7 & 1 & N.D. & N.D. & N.D. & N.D. \\
\hline Tambaú & SP & 19.5 & N.D. & N.D. & N.D. & N.D. & N.D. & N.D. \\
\hline S.C. das Palmeiras & SP & 19.6 & N.D. & N.D. & N.D. & N.D. & N.D. & N.D. \\
\hline Varg. Grde. do Sul & SP & 19.7 & N.D. & N.D. & N.D. & N.D. & N.D. & N.D. \\
\hline Mogi Guaçu & SP & 20.2 & N.D. & N.D. & N.D. & N.D. & N.D. & N.D. \\
\hline S. C. das Palmeiras & SP & 20.3 & N.D. & N.D. & N.D. & N.D. & N.D. & N.D. \\
\hline Porto Ferreira & SP & 20.3 & 18 & 2 & N.D. & N.D. & N.D. & N.D. \\
\hline Aguar & SP & 20.3 & 7 & 1 & N.D. & N.D. & N.D. & N.D. \\
\hline Aguai & SP & 20.4 & N.D. & N.D. & N.D. & N.D. & N:D. & N.D. \\
\hline Estiva Gerbi & SP & 20.4 & N.D. & N.D. & N.D. & N.D. & N.D. & N.D. \\
\hline Estiva Gerbi & SP & 20.5 & N.D. & \begin{tabular}{l|l} 
N.D. \\
\end{tabular} & \begin{tabular}{l|l} 
N.D. \\
\end{tabular} & N.D. & N.D. & N.D. \\
\hline Porto Ferreira & SP & 20.5 & N.D. & N.D. & N.D. & N.D. & N.D. & N.D. \\
\hline Varg. Grde. do Sul & SP & 20.7 & N.D. & N.D. & N.D. & N.D. & N.D. & N.D. \\
\hline Chapadão do Sul & MS & 20.9 & N.D. & N.D. & N.D. & N.D. & N.D. & N.D. \\
\hline Leme & SP & 21.0 & N.D. & N.D. & N.D. & N.D. & N.D. & N.D. \\
\hline Varg. Grde. do Sul & SP & 21.0 & N.D. & N.D. & N.D. & N.D. & N.D. & N.D. \\
\hline Aguai & SP & 21.1 & N.D. & N.D. & N.D. & N.D. & N.D. & N.D. \\
\hline Limeira & SP & 21.3 & N.D. & N.D. & N.D. & N.D. & N.D. & N.D. \\
\hline S.C. das Palmeiras & SP & 21.4 & N.D. & N.D. & N.D. & N.D. & N.D. & N.D. \\
\hline Casa Branca & SP & 21.4 & N.D. & N.D. & N.D. & N.D. & N.D. & N.D. \\
\hline Casa Branca & SP & 21.8 & N.D. & N.D. & N.D. & N.D. & N.D. & N.D. \\
\hline Casa Branca & SP & 22.2 & N.D. & N.D. & N.D. & N.D. & N.D. & N.D. \\
\hline Varg. Grde. do Sul & SP & 22.6 & N.D. & N.D. & N.D. & N.D. & N.D. & N.D. \\
\hline Casa Branca & SP & 22.6 & N.D. & N.D. & N.D. & N.D. & N.D. & N.D. \\
\hline Varg. Grde. do Sul & SP & 22.8 & N.D. & N.D. & N.D. & N.D. & N.D. & N.D. \\
\hline Casa Branca & SP & 22.8 & N.D. & N.D. & N.D. & N.D. & N.D. & N.D. \\
\hline Varg. Grde. do Su I & SP & 23.0 & N.D. & N.D. & N.D. & N.D. & N.D. & N.D. \\
\hline
\end{tabular}


Continuação da Tabela 2.

\begin{tabular}{|c|c|c|c|c|c|c|c|c|}
\hline Procedéncia & U.F. & $\begin{array}{c}\text { Umidade } \\
\%\end{array}$ & $\begin{array}{l}\text { AFLA } \\
B_{1}\end{array}$ & $\mathbf{B}_{\mathbf{2}}$ & $\begin{array}{l}\text { AFLA } \\
\mathbf{G}_{1} \\
\text { lkg }\end{array}$ & $\begin{array}{l}\text { AFLA. } \\
\mathbf{O}_{2}\end{array}$ & $\begin{array}{l}\text { OCRATOXINA A } \\
\quad \mu g l k g\end{array}$ & $\begin{array}{l}\text { ZEARALENONA } \\
\text { rglkg }\end{array}$ \\
\hline Casa Branca & SP & 23.2 & N.D. & N.D. & N.D. & N.D. & N.D. & N.D. \\
\hline Varg. Grde. do Sul & SP & 23.2 & N.D. & N.D. & N.D. & N.D. & N.D. & N.D. \\
\hline Casa Branca & SP & 23.6 & N.D. & N.D. & N.D. & N.D. & N.D. & N.D. \\
\hline Leme & SP & 23.9 & N.D. & N.D. & N.D. & N.D. & N.D. & N.D. \\
\hline Varg. Grde. do Sul & SP & 24.0 & N.D. & N.D. & N.D. & N.D. & N.D. & N.D. \\
\hline Araras & SP & 24.0 & N.D. & N.D. & N.D. & N.D. & N.D. & N.D. \\
\hline Casa Branca & SP & 24.1 & 5 & N.D. & 3 & N.D. & N.D. & N.D. \\
\hline Apar. do Taboado & MS & 24.1 & 3 & N.D. & N.D. & N.D. & N.D. & N.D. \\
\hline Varg. Grde. do Sul & SP & 24.3 & N.D. & N.D. & N.D. & N.D. & N.D. & N.D. \\
\hline Casa Branca & SP & 24.8 & N.D. & N.D. & N.D. & N.D. & N.D. & N.D. \\
\hline Casa Branca & SP & 24.9 & N.D. & N.D. & N.D. & N.D. & N.D. & N.D. \\
\hline S.C.das Palmeiras & SP & 25.6 & N.D. & N.D. & N.D. & N.D. & N.D. & N.D. \\
\hline Casa Branca & SP & 25.9 & N.D. & N.D. & N.D. & N.D. & N.D. & N.D. \\
\hline Varg. Grde. do Sul & SP & 28.2 & N.D. & N.D. & N.D. & N.D. & N.D. & N.D. \\
\hline Varg. Grde. do Sul & SP & 29.0 & 7 & N.D. & N.D. & N.D. & N.D. & N.D. \\
\hline Casa Branca & SP & 29.1 & N.D. & N.D. & N.D. & N.D. & N.D. & N.D. \\
\hline Apar. do Taboado & MS & 30.6 & N.D. & N.D. & N.D. & N.D. & N.D. & N.D. \\
\hline $\begin{array}{c}\text { Contaminação } \\
\text { Média* }^{*} \\
\mu g / k g\end{array}$ & & & 8,7 & 1,4 & 30,6 & 6 & ------- & ------- \\
\hline $\begin{array}{c}\text { Amostras } \\
\text { Contaminadas }\end{array}$ & & & $\begin{array}{c}18 \\
(16,8 \%)\end{array}$ & $\begin{array}{c}7 \\
(6,5 \%)\end{array}$ & $\begin{array}{c}3 \\
(2,8 \%)\end{array}$ & $\begin{array}{c}1 \\
(0,09 \%)\end{array}$ & ------- & ------- \\
\hline $\begin{array}{c}\text { Amplitude de } \\
\text { variação } \\
\mu g / k g\end{array}$ & & & $3-58$ & $1-2$ & $3-85$ & 6 & ---------- & ------- \\
\hline
\end{tabular}

* Média das amostras contaminadas.

N.D. - Não detectada. 
Tabela 3 - Procedência, umidade de entrada na indústria e resultados da contaminação com micotoxinas, dos 90 carregamentos amostrados em agosto de 1994.

\begin{tabular}{|c|c|c|c|c|c|c|c|c|}
\hline Procedéncia & U.F. & Umidode $\%$ & $\begin{array}{c}\text { AFLA } \\
\text { B }_{1}\end{array}$ & $\begin{array}{l}\text { AFLA. } \\
\text { B }_{2}\end{array}$ & $\begin{array}{l}\text { AFLA } \\
G_{1} \\
\text { k } g\end{array}$ & $\begin{array}{c}\text { AFLA. } \\
G_{2}\end{array}$ & $\begin{array}{c}\text { OCRATOXINA A } \\
\mu g / k g\end{array}$ & $\begin{array}{l}\text { ZEARALENONA } \\
\mu g l k g\end{array}$ \\
\hline Jaciara & MT & 12.2 & 3 & N.D. & N.D. & N.D. & N.D. & N.D. \\
\hline Chap. do Sul & MS & 12.0 & N.D. & N.D. & N.D. & N.D. & N.D. & N.D. \\
\hline Dourados & MS & 14.1 & N.D. & N.D. & N.D. & N.D. & N.D & N.D. \\
\hline Uberlândia & MG & 11.9 & N.D. & N.D. & N.D. & N.D. & N.D. & N.D. \\
\hline Uberlândia & MG & 12.3 & N.D. & N.D. & N.D. & N.D. & N.D & N.D. \\
\hline Jaciara & MT & 14.3 & N.D. & N.D. & N.D. & N.D. & N.D & N.D. \\
\hline Uberlândia & MG & 11.6 & N.D. & N.D. & N.D. & N.D. & N.D & N.D. \\
\hline Dourados & MS & 12.0 & N.D. & N.D. & N.D. & N.D. & N.D & N.D. \\
\hline Jaciara & MT & 14.5 & 3 & N.D. & N.D. & N.D. & N.D & N.D. \\
\hline Fenix & PR & 14.5 & N.D. & N.D. & N.D. & N.D. & N.D. & N.D. \\
\hline Fenix & PR & 15.0 & 7 & N.D. & N.D. & N.D. & N.D. & N.D. \\
\hline P. do Leste & MT & 13.4 & 5 & 1 & N.D. & N.D. & N.D. & N.D. \\
\hline Jaciara & MT & 14.8 & N.D. & N.D. & N.D. & N.D. & N.D & N.D. \\
\hline Fenix & PR & 14.3 & 7 & N.D. & N.D. & N.D. & N.D & N.D. \\
\hline Ituverava & SP & 15.1 & N.D. & N.D. & N.D. & N.D. & N.D & N.D. \\
\hline Formosa & GO & 12.8 & N.D. & N.D. & N.D. & N.D. & N.D & N.D. \\
\hline Formosa & GO & 14.2 & 3 & N.D. & N.D. & N.D. & N.D & N.D. \\
\hline Dourados & MS & 11.5 & 11 & 1 & N.D. & N.D. & N.D & N.D. \\
\hline Ituverava & SP & 13.9 & N.D. & N.D. & N.D. & N.D. & N.D & N.D. \\
\hline Ituverava & SP & 14.0 & N.D. & N.D. & N.D. & N.D. & N.D & N.D. \\
\hline P. do Leste & MT & 14.8 & N.D. & N.D. & N.D. & N.D. & N.D & N.D. \\
\hline P. do Leste & MT & 14.5 & N.D. & N.D. & N.D. & N.D. & N.D & N.D. \\
\hline Sertaneja & PR & 14.9 & 5 & N.D. & N.D. & N.D & N.D. & N.D. \\
\hline Dourados & MS & 14.2 & 3 & N.D. & N.D. & N.D. & N.D & N.D. \\
\hline Fenix & PR & 14.2 & N.D. & N.D. & N.D. & N.D. & N.D & N.D. \\
\hline P. do Leste & MT & 12.2 & N.D. & N.D. & N.D. & N.D. & N.D & N.D. \\
\hline Campo Grande & MS & 13.5 & N.D. & N.D. & N.D. & N.D. & N.D & N.D. \\
\hline Quirinopolis & GO & 13.9 & N.D. & N.D. & N.D. & N.D. & N.D & N.D. \\
\hline Campo Mourão & PR & 13.9 & N.D. & N.D. & N.D. & N.D. & N.D & N.D. \\
\hline
\end{tabular}


Continuação da Tabela 3.

\begin{tabular}{|c|c|c|c|c|c|c|c|c|}
\hline Procedência & U.F. & Umidade $\%$ & $\begin{array}{c}\text { AFLA } \\
B_{1}\end{array}$ & $\begin{array}{l}\text { AFLA. } \\
B_{2} \\
\mu g 1\end{array}$ & $\begin{array}{l}\text { AFLA } \\
G_{1}\end{array}$ & $\begin{array}{c}\text { AFLA. } \\
\mathbf{O}_{2}\end{array}$ & $\begin{array}{c}\text { OCRATOXINA A } \\
\mu g l k g\end{array}$ & 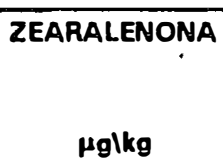 \\
\hline Arapongas & PR & $12 . .8$ & N.D. & N.D. & N.D. & N.D. & N.D & N.D. \\
\hline Arapongas & PR & 12.9 & N.D. & N.D. & N.D. & N.D. & N.D & N.D. \\
\hline Campo Grande & MS & 13.9 & N.D. & N.D. & N.D. & N.D. & N.D & N.D. \\
\hline Patr. Paulistal & SP & 11.2 & N.D. & N.D. & N.D. & N.D. & N.D & N.D. \\
\hline Jaciara & MT & 14.2 & N.D. & N.D. & N.D. & N.D. & N.D & N.D. \\
\hline Itaberaf & GO & 13.9 & N.D. & N.D. & N.D. & N.D. & N.D & N.D. \\
\hline P. do Leste & MT & 12.8 & 7 & N.D. & N.D. & N.D. & N.D & N.D. \\
\hline Jaciara & MT & 14.0 & N.D. & N.D. & N.D. & N.D. & N.D & N.D. \\
\hline Jaciara & MT & 14.1 & N.D. & N.D. & N.D. & N.D. & N.D & N.D. \\
\hline P. do Leste & MT & 12.8 & 3 & N.D. & N.D. & N.D. & N.D & N.D. \\
\hline Sertaneja & PR & 14.3 & N.D. & N.D. & N.D. & N.D. & N.D & N.D. \\
\hline Sertaneja & PR & 14.9 & 3 & N.D. & N.D. & N.D. & N.D & N.D. \\
\hline Dourados & MS & 13.7 & N.D. & N.D. & N.D. & N.D. & N.D & N.D. \\
\hline P. do Leste & MT & 12.6 & 3 & N.D. & N.D. & N.D. & N.D & N.D. \\
\hline Campo Grande & MS & 13.6 & 5 & N.D. & N.D. & N.D. & N.D & N.D. \\
\hline Campo Mourão & PR & 14.9 & 5 & N.D. & N.D. & N.D. & N.D & N.D. \\
\hline Jaciara & MT & 14.3 & N.D. & N.D. & N.D. & N.D. & N.D & N.D. \\
\hline Campo Grande & MS & 12.7 & N.D. & N.D. & N.D. & N.D. & N.D & N.D. \\
\hline Campo Grande & MS & 13.0 & 3 & N.D. & N.D. & N.D. & N.D & N.D. \\
\hline Sertaneja & PR & 15.0 & N.D. & N.D. & N.D. & N.D. & N.D & N.D. \\
\hline Quirinopólis & GO & 14.9 & 5 & N.D. & N.D. & N.D. & N.D & N.D. \\
\hline Quirinopólis & GO & 12.0 & N.D. & N.D. & N.D. & N.D. & N.D & N.D. \\
\hline Ituverava & SP & 13.8 & N.D. & N.D. & N.D. & N.D. & N.D & N.D. \\
\hline Ituverava & SP & 14.1 & N.D. & N.D. & N.D. & N.D. & N.D & N.D. \\
\hline Ituverava & SP & 14.0 & N.D. & N.D. & N.D. & N.D. & N.D & N.D. \\
\hline Campo Grande & MS & 11.4 & N.D. & N.D. & N.D. & N.D. & N.D & N.D. \\
\hline Campo Mourão & PR & 15.1 & N.D. & N.D. & N.D. & N.D. & N.D & N.D. \\
\hline Ituverava & SP & 14.6 & 6 & N.D. & N.D. & N.D. & N.D & N.D. \\
\hline Campo Grande & MS & 12.7 & 3 & N.D. & N.D. & N.D. & N.D & N.D. \\
\hline
\end{tabular}


Continuação da Tabela 3.

\begin{tabular}{|c|c|c|c|c|c|c|c|c|}
\hline Procedéncia & U.F. & Umidade \% & $\begin{array}{c}\text { AFLA. } \\
8_{1}\end{array}$ & $\begin{array}{c}\text { AFLA. } \\
B_{2}\end{array}$ & $\begin{array}{l}\text { AFLA. } \\
\text { G, } \\
\text { olkg }\end{array}$ & $\begin{array}{c}\text { AFLA. } \\
G_{2}\end{array}$ & $\begin{array}{l}\text { OCRATOXINA A } \\
\text { Hglkg }\end{array}$ & $\begin{array}{c}\text { ZEARALENONA } \\
\text { Hglkg }\end{array}$ \\
\hline Jaciara & MT & 13.1 & N.D. & N.D. & N.D. & N.D. & N.D & N.D. \\
\hline Ituverava & SP & 14.1 & N.D. & N.D. & N.D. & N.D. & N.D & N.D. \\
\hline Arapongas & PR & 13.1 & 3 & N.D. & N.D. & N.D. & N.D & N.D. \\
\hline Arapongas & PR & 11.5 & 5 & N.D. & N.D. & N.D. & N.D & N.D. \\
\hline Campo Mourão & PR & 15.2 & 3 & N.D. & N.D. & N.D. & N.D & N.D. \\
\hline Sertaneja & PR & 14.4 & N.D. & N.D. & N.D. & N.D. & N.D & N.D. \\
\hline Arapongas & PR & 12.8 & N.D. & N.D. & N.D. & N.D. & N.D & N.D. \\
\hline Campo Grande & MS & 13.1 & N.D. & N.D. & N.D. & N.D. & N.D & N.D. \\
\hline Arapongas & PR & 12.9 & N.D. & N.D. & N.D. & N.D. & N.D & N.D. \\
\hline Ituverava & SP & 14.6 & N.D. & N.D. & N.D. & N.D. & N.D & N.D. \\
\hline Ituverava & SP & 14.7 & N.D. & N.D. & N.D. & N.D. & N.D & N.D. \\
\hline Formosa & GO & 13.8 & N.D. & N.D. & N.D. & N.D. & N.D & N.D. \\
\hline Ituverava & SP & 14.2 & N.D. & N.D. & N.D. & N.D. & N.D & N.D. \\
\hline Ituverava & SP & 14.6 & N.D. & N.D. & N.D. & N.D. & N.D & N.D. \\
\hline Ituverava & SP & 14.5 & N.D. & N.D. & N.D. & N.D. & N.D & N.D. \\
\hline Ituverava & SP & 14.5 & N.D. & N.D. & N.D. & N.D. & N.D & N.D. \\
\hline Ituverava & SP & 14.3 & N.D. & N.D. & N.D. & N.D. & N.D & N.D. \\
\hline Formosa & GO & 13.3 & N.D. & N.D. & N.D. & N.D. & N.D & N.D. \\
\hline Ituverava & SP & 14.7 & N.D. & N.D. & N.D. & N.D. & N.D & N.D. \\
\hline P. do Leste & MT & 12.9 & N.D. & N.D. & N.D. & N.D. & N.D & N.D. \\
\hline Ituverava & SP & 14.1 & N.D. & N.D. & N.D. & N.D. & N.D & N.D. \\
\hline Ituverava & SP & 13.9 & N.D. & N.D. & N.D. & N.D. & N.D. & N.D. \\
\hline Ituverava & SP & 13.6 & N.D. & N.D. & N.D. & N.D. & N.D. & N.D. \\
\hline Ituverava & SP & 14.5 & N.D. & N.D. & N.D. & N.D. & N.D. & N.D. \\
\hline Campo Grande & MS & 13.2 & N.D. & N.D. & N.D. & N.D. & N.D. & N.D. \\
\hline Campo Mourão & PR & 14.6 & N.D. & N.D. & N.D. & N.D. & N.D. & N.D. \\
\hline Campo Mourão & PR & 14.2 & 3 & N.D. & N.D. & N.D. & N.D. & N.D. \\
\hline Campo Mourão & PR & 14.6 & 3 & N.D. & N.D. & N.D. & N.D. & N.D. \\
\hline Campo Grande & MS & 12.4 & N.D. & N.D. & N.D. & N.D. & N.D. & N.D. \\
\hline |Campo Mourão & PR & 14.8 & N.D. & N.D. & N.D. & N.D. & N.D. & N.D. \\
\hline
\end{tabular}


Continuação da Tabela 3.

\begin{tabular}{|c|c|c|c|c|c|c|c|c|}
\hline Procedéncio & U.F. & midade $\%$ & $\begin{array}{cc}\text { AFLA. } & \text { AFI } \\
B_{1} & B\end{array}$ & $\begin{array}{r}A \quad \text { AFL } \\
0 \\
\mu g\end{array}$ & & LA. & $\begin{array}{c}\text { OCRATOXINA A } \\
\text { molkg }\end{array}$ & $\begin{array}{c}\text { ZEARALENONA } \\
\mu g / k g\end{array}$ \\
\hline Campo Grande & MS & 14.4 & N.D. & N.D. & N.D. & N.D. & N.D. & N.D. \\
\hline Campo Grande & MS & 13.0 & 3 & N.D. & N.D. & N.D. & N.D. & N.D. \\
\hline $\begin{array}{c}\text { Contaminação } \\
\text { Média* }^{*} \\
\mu \mathrm{g} / \mathrm{kg}\end{array}$ & & & 4,4 & 1,0 & 0 & 0 & -..--..-- & ---.--- \\
\hline $\begin{array}{c}\text { Amostras } \\
\text { Contaminadas }\end{array}$ & & & $\begin{array}{c}25 \\
(27,7 \%)\end{array}$ & $\begin{array}{c}2 \\
(2,2 \%)\end{array}$ & $\begin{array}{c}0 \\
(0 \%)\end{array}$ & $\begin{array}{c}0 \\
(0 \%)\end{array}$ & -..---.-- & -..--- \\
\hline $\begin{array}{c}\text { Amplitude de } \\
\text { variaçâao } \\
\mu \mathrm{g} / \mathrm{kg}\end{array}$ & & & $3-11$ & -...- & $\ldots$ & -.-... & -............ & -.....-- \\
\hline
\end{tabular}

* Média das amostras contaminadas

N.D. - Não detectada.

Tabela 4 - Número de amostras recebidas com umidade igual ou maior que $14,5 \%$ e igual ou maior que $16 \%$.

\begin{tabular}{c|c|c}
\hline $\begin{array}{c}\text { Periodo da } \\
\text { amostragem }\end{array}$ & Umidade $\geq 14,5 \%$ & Umidade $\geq 16 \%$ \\
\hline $1^{\mathrm{a}}$ (Outubro/93) & $49(51 \%)^{\star}$ & $25(26,0 \%)$ \\
\hline $2^{\mathrm{a}}$ (Março/94) & $71(66,9 \%)$ & $61(57,5)$ \\
\hline $3^{\mathrm{a}}$ (Agosto/94) & $25(27,7 \%)$ & 0 \\
\hline
\end{tabular}

* Percentage sobre o total de amostras em cada amostragem.

Tabela 5 - Contaminação média e valor máximo da contaminação, em $\mu \mathrm{g} / \mathrm{kg}$, considerando a soma das aflatoxinas $B_{1}+G_{1}$, em cada amostragem.

\begin{tabular}{l|c|c}
\hline $\begin{array}{c}\text { Período da } \\
\text { amostragem }\end{array}$ & Contaminação média * & $\begin{array}{c}\text { Valor máximo da } \\
\text { contaminação }\end{array}$ \\
\hline $1^{\mathrm{a}}$ (Outubro/93) & 14,9 & 107 \\
\hline $2^{\mathrm{a}}$ (Março/94) & 13,9 & 143 \\
\hline $3^{\mathrm{a}}$ (Agosto/94) & 4,3 & 11 \\
\hline
\end{tabular}

* Média das amostras contaminadas. 


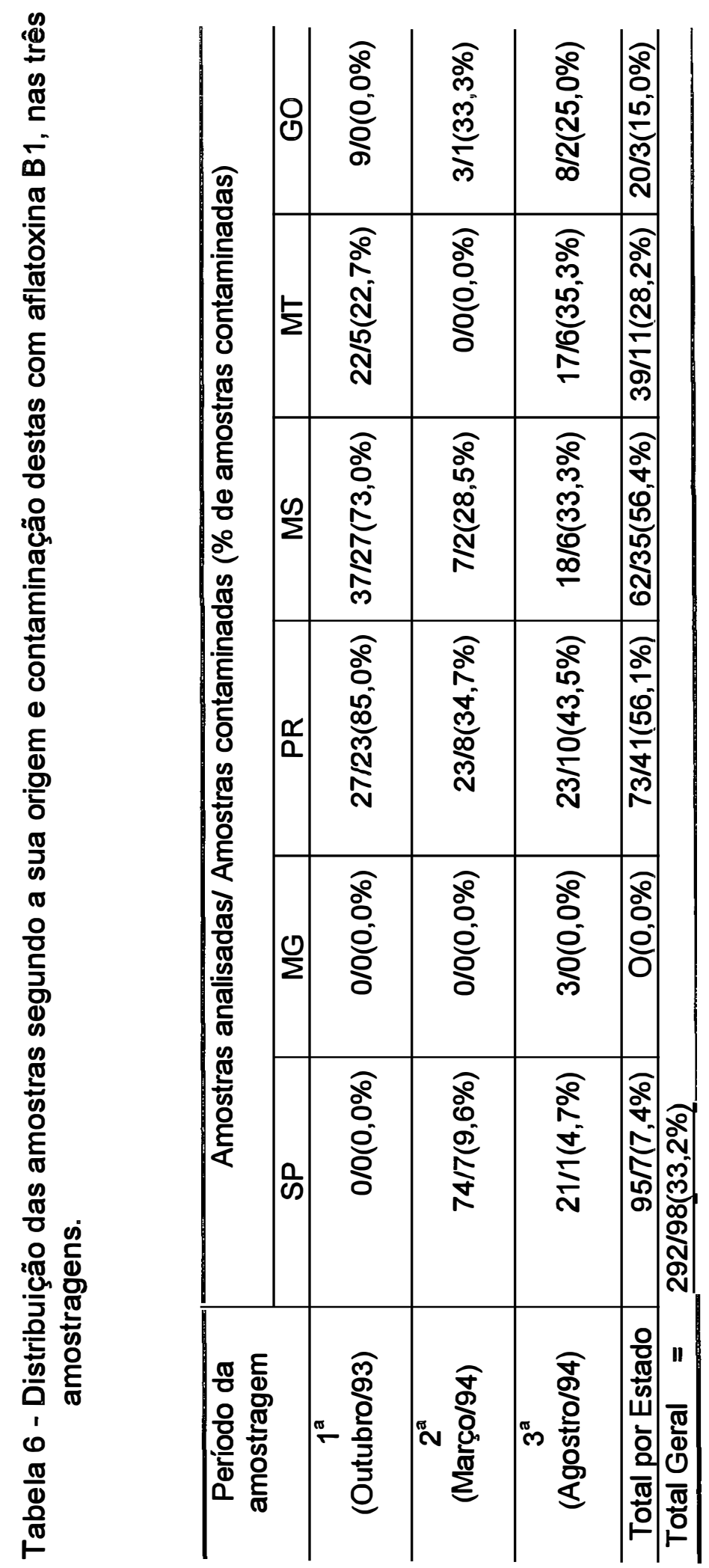




\section{REFERÊNCIAS BIBLIOGRÁFICAS}

ALMEIDA, R.M.A. Avaliação dos Efeitos Agudos Produzidos por Aflatoxina B1 em Diferentes Linhagens de Camundongos Isogênicos. São Paulo, 1994. 125p. (Doutarado - Instituto de Ciências Biomédicas/USP).

AMLA, I.; PARPIA, H.A.B; JAYARAJ, A.P. Cirrhosis in children after consumption of aflatoxin-contaminated peanut meal. Journal of Pathology,Chichester, 103(2):19, 1971. Apud MEHAN,F.K.; McDONALD,D.; HARAVU, L.J.; JAYANTHI, S. The groundnut problem: review and literature database. Patancheru, International Crops Institute for the Semi-Arid Tropics, 1991. p.24 (Resumo).

AMLA, I.; KUMARI, S.; SREENIVASAMURTHY, F.; JAYARAJ, A.P.; PARPIA, H.A.B. Role of aflatoxin in Indian childhood cirrhosis. Indian Pediatrics, New Delhi, 7(5): 262-270, 1970. Apud MEHAN, .K.; McDONALD, D.; HARAVU, L. J.; JAYANTHI, S. The groundnut problem: review and literature database. Patancheru, International Crops Institute for the SemiArid Tropics, 1991. p.24 (Resumo).

ANDERSON, H.A.; NEHRING, E. W.; WICHSER, W.R. Aflatoxin contamination of com in the field. Journal of Agricultural and Food Chemical, Washignton, 23: 775, 1975

BALDISSERA, M.A.; SANTURIO, J.M.; SILVA, J.B.; ALMEIDA, C.A.A. Aflatoxinas, ocratoxina $A$ e zearalenona em grãos e rações para consumo animal no sul do Brasil. Ciência e Tecnologia Alimentos, Campinas, 12(1):77-82, jan./jun. 1992.

BARRY, D. Insects of Maize and their association with aflatoxin contamination. In: ZUBER, M.S.; LILLEHOJ, E.B.; RENFRO, B.L. eds. Aflatoxin in maize: a proceedings of the workshop, El Batan, CIMMYT, 1986. p.201-11. 
BECROFT, D.M.O.; WEBSTER, D.R. Aflatoxins and Reye's disease. British Medical Journal, London, 4: 117, 1972.

BENNETT, G. \& ANDERSON, R. A. Distribution of aflatoxin and/or zearalenone in wet-milled corn. Journal of Agricultural and Food Chemistry, Easton, 26(5):1055-60, 1978.

BENNETT, G.A. \& SHOTWELL, O.L. Zearalenone in cereal grains. Journal of the American Oil Chemists Society, Chicago, 56:812-9, 1979.

BRADBURN, N.; BLUNDEN, G.; COKER, R.D.; JEWERS, K. Aflatoxin contamination of maize. Tropical Science, Dorchester, 33(4):418-28, 1993.

BRASIL. Leis, decretos, etc. Resolução $n^{\circ} 34 / 76$ da Comissão Nacional de Normas e Padrões para Alimentos. Diário Oficial, Brasília, 19 jan. 1977. Seção I, pt. I, p.710. Fixa padrōes de tolerância para aflatoxinas em alimentos.

BRASIL. Ministério da Agricultura. Departamento de Produção Vegetal. Divisão de Sementes e Mudas. Regras para análise de semente. Brasilia, 1980. 188p.

BOURGEOIS, C.H.; SHANK, R.G.; GROSSMAN, R.A.; JOHSEN, D.O.; WOODING, W.L.; CHANDAVINOL, P. Acute aflatoxin $B_{1}$ toxicity in the macaque and its similarities to Rey's syndrome. Laboratory Investigation, Londres, 24: 206-16, 1971.

BULLERMAN, L.B.; SCHROEDER, L.L.; PARK, K.Y. Formation and control of mycotoxins in food. Journal of Food Protection, Ames, 47(8): 637-46, 1984.

CAMPBELL, T.C. \& STOLOFF, L. Implication of mycotoxins for humans health. Journal of Agricultural and Food Chemical, Washington, 22: 1006-14, 1974.

CARDENAS, O.S. \& PLATA, O. Evaluation of aflatoxin $B_{1}$, in the departament of Meta (Colombia). Tecnologia, Bogota, 26(159):34-43, $1986 . \quad$ Apud Food Science And Technology Abstracts, Berlim, 20(12):112, 1988.

CARNAGHAN, R.B.; HARTLEY, R.D.; OKELLY, J. Toxicity and fluorescence properties of the aflatoxins. Nature, London, 200 (4911): 1101, 1963. 
CELARO, J.C. Unidades armazenadoras a nivel de propriedade. In: CONGRESSO NACIONAL DO MILHO E SORGO, 19., Porto Alegre, 1992. Conferências. Porto Alegre, SAA, 1992. p. 234-46.

CHELACK, W.S.; BORSA, J.; MARQUARDT, R.R.; FROLICH, A.A. Role of competitive microbial flora in the radiation induced enhancement of ochratoxin production by Aspergillus alutaceus var. alutaceus NRRL 3174. Applied and Enviromental Microbiology, Baltimore, 57:2492, 1991.

CHEN, J.C.; CAMPBELL, T.C.; LEE, J.; PETO, R. A preliminary study of dietary, life style, and mortality characteristics of 65 rural populations in the people's Republic of China. Oxford University Press, New York.1990. Apud MEHAN,F.K.; McDONALD, D.; HARAVU, L.J.; JAYANTHI, S. The groundnut problem: review and literature database. Patancheru, International Crops Institute for the Semi-Arid Tropics, 1991 . p.28 (Resumo).

COGO, C.H. Perspectivas e tendências para o milho na região sul e no Brasil. In:CONGRESSO NACIONAL DO MILHO E SORGO, 19, Porto Alegre, 1992. Conferências. Porto Alegre, SAA, 1992. p. 71-80.

COULTER, J.B.S.; SULIMAN, G.L.; LAMPLUGH, S.M.; MUKHTAR, B.I.; HENDRICKSE,R.G. Aflatoxins in liver biopsies from Sudanese children. American Journal of Tropical Medicine and Hygiene, Baltimore, 35(2): 360-5, 1986. Apud MEHAN,F.K.; McDONALD, D.; HARAVU, L.J.; JAYANTHI, S. The groundnut problem: review and literature database. Patancheru, International Crops Institute for the Semi-Arid Tropics, 1991. p.28 (Resumo).

DIENER, U.L.; COLE, R.J.; SANDERS, T.H.; PAYNE, G.A.; LEE, L.S.; KLICH, M.A. Epidemiology of aflatoxin formation by Aspergillus flavus. Annual Review Phytopathology, Palo Alto, 25 : 249-70, 1987 (Resumo).

DVALI, G.N. Aflatoxins content in foods of vegetables origin in the Georgia SSR. Voprosy Pitaniya, Tbilisi, 2:68-9, 1983. Apud Food Science and Technology Abstracts, Berlim, 16(7):19, 1984.

EGAN, H. ed. Envirommental carcinogens selected methods of analysis. Lyon, International Agency for Research on Cancer, 1982. v.5, 456p.

EPPLEY, R.M.; STOLOFF, L.; TRUCKSESS, M.W. Survey of corn for Fusarium toxins. Journal of the Association of Official Analytical Chem ists, Washington, 57(3):632-5, 1974. 
EUGENIO, C.P.; CHRISTENSEN, C.M.; MIROCHA, C.J. Factors affecting production of the mycotoxin F-2 by Fusarium roseum. Phytopathology, Lancaster, 60:1055-7, 1970.

FANCELLI, L.A. Pré-processamento. In: FANCELLI, L.A. \& LIMA, U.A., ed. Milho; produção, pré-processamento e transformação agroindustrial. São Paulo, Secretaria da Indústria, Comércio, Ciência e Tecnologia, 1982. 112p. (Extensão Agroindustrial,5).

FIORENTINI, L.; FREITAS, A.R.; FIALHO, E.T. Contaminação por aflatoxinas em milho utilizado em raçōes para suínos. Pesquisa Agropecuária Brasileira, Brasília, 24(10):1211-6, 1989.

FONSECA, H. Contribuição ao estudo da aflatoxina no amendoim Arachis hypogaea L. da colheita à industrialização. Piracicaba, 1969. 81p. (Livre Docência-Escola Superior de Agricultura "Luiz de Queiroz"/USP).

FONSECA, H. \& del NERY, H. Ocorrência de aflatoxina em pasta de amendoim (Arachis hipogaea L.). Anais Escola Superior de Agricultura "Luiz de Queiroz", Piracicaba, 27: 181-190, 1970.

FONSECA, H.; NOGUEIRA, J.N.; GRANER, M.; OLIVEIRA, A.J.; CARUSO, J.G.B.; BORALLI, M.A.; CALORI, M.A.; KHATOUNIAN, C.A. Natural ocurrence of mycotoxins in some Brazilian foods. In: INTERNATIONAL IUPAC SYMPOSIUMON MYCOTOXIN AND PHYCOTOXINS, 50, Viena, 1982. Proceedings. Viena, World Health Organization, 1982. p.76-9.

FONSECA, H.; NOGUEIRA, J.N.; GRANER, M.; OLIVEIRA, A.J.; CARUSO, J.G.B.; BORALLI, M.A.; CALORI, M.A.; KHATOUNIAN, C.A. Natural occurrence of mycotoxins in some Brazilian foods. Part II. In: WORLD CONGRESS OF FOOD SCIENCE AND TECHNOLOGY, 6., Dublin, 1983. Proceedings. Dublin, Boole Press, 1983. p. 53-4.

FORTNUM, B.A. Effect of environment on aflatoxin development in preharvest maize. In:ZUBER, M.S.; LILLEHOJ, E.B.; RENFRO, B.L. eds. Aflatoxin in maize: a proceedings of the workshop, El Batan, CIMMYT, 1986. p.14551.

GOLINSKI, P. \& GRABARKIEWICZ-SZCZENA, J. Chemical confirmatory tests for ochratoxin A, citrinin, penicillic acid, sterigmatocystin, and zearalenone performed directly on thim layer chromatographic plates. Journal of the Associtation of Official Analytical Chemists, Arlington, 67(6):1108-10, 1984. 
HALD, B. Human exposure to ochratoxin A. In: MYCOTOXINS AND PHYCOTOXINS'1988. Amsterdam, 1988. Amsterdam, Elsevier, 1989. p.57-68. (Bioactive Molecules, 10).

HAYES, A.W. Involvement of mycotoxins in animal and human health. In: HAYES, A.W. Mycotoxin teratogenicity and mutagenicity. Boca Raton, CRC Press, 1981. cap.2, p.11-40.

HEATHCOTE, J.G. Aflatoxins and related toxins. In: BETINA, V. ed. Mycotoxins; production, isolation, separation and purification, Amsterdam, Elsevier, 1984. p.89-130.

HENDRICKSE, R.G. The influence of aflatoxins on child health in the tropics with particular reference to kwashiorkor. Transactions of the Royal Society of Tropical Medicine and Hygiene, London, 78 (4): 427-35, 1984.

HESSELTINE, C.W.; SORENSON, W.G.; SMITH, M. Taxonomic studies of the aflatoxin-producing strains in the Aspergillus flavus group. Mycologia, Lancaster, 62:123-32, 1970.

HSIEH, D.P.H.; WONG, Z.A.; WONG, J.M.; HICHAS, C.; RUEBNER, B.H. Comparative Metabolism of Aflatoxin. In: RODRICIS, J.V.; HESSELTINE, C.W.; MEHLMAN, M.A., ed. Mycotoxins in human and animal health. Park Forest South, Pathotox Publ., 1977. p37-50.

JARVIS, B. Factors affecting the production of mycotoxins. Journal Applied Bacteriology, Oxford, 34:199, 1971.

JELINEK, C.F. Distribuition of mycotoxin - an analysis of world wide commodities data, including data from FAO/WHO/UNEP food contamination monitoring programme. In: INTERNATIONAL CONFERENCE ON MYCOTOXINS, 2., Bangkok, 1987. Roma, FAO/WHO/UNEP, 1988, 49p.

JELINEK, C.F.; POHLAND, A.E.; WOOD,G. Worldwide occurence of mycotoxins in foods and feeds an update. Journal of the Association of Official Analytical Chemists, Arlington, 72(2): 224-30, 1989.

JOFFE, A.Z. Fusarium species their biology and toxicology. New York, John Wiley \& Sons, 1986. 588p.

JONES, R.K.; DUNCAN, H.E.; PAYNE, G.A.; LEONARD, K. J. Factors influencing infection by Aspergillus flavus in silk-inoculated corn. Plant Disease, Sant Paul, 64(9): 859-63, 1980. 
JONES, R.K. The influence of cultural pratices on minimizing the development of aflatoxin in field maize. In: ZUBER, M.S.; LILLEHOJ, E.B.; RENFRO, B.L. eds. Aflatoxin in maize: a proceedings of the workshop, El Batan, CIMMYYT, 1986. p.136-44.

KOUDELA, S.; SOÓS, K.; SOHÁR, J.; BIRÓ,G. The assessment of zearalenone exposition of the hungarian population in connection with fusarium infected cereals. Acta Alimentaria, Budapeste, 19(3):229-35, 1990.

KRISHNAMACHARI, K.A.V.R.; BHAT, R.V.; NAGARAJAN, V.;TILAK, T.B.G. Hepatitis due to aflatoxicosis - An outbreak in Western India. Lancet, London, 1061-1063, 1975a. Apud MEHAN, F.K.; McDONALD, D.; HARAVU, L.J.; JAYANTHI, S.The groundnut problem: review and literature database. Patancheru, International Crops Institute for the SemiArid Tropics, 1991. p.32 (Resumo).

KRISHNAMACHARI, K.A.V.R.; BHAT, R.V.; NAGARAJAN, V.;TILAK, T.B.G. Investigation into an outbreak of hepatitis in parts of Western India. Indian Journal of Medical Research, New Delhi, 63: 1036-1049, 1975b. Apud MEHAN,F.K.; McDONALD, D.; HARAVU, L.J.; JAYANTHI, S. The groundnut problem: review and literature database. Patancheru, International Crops Institute for the Semi-Arid Tropics, $1991 . \quad$ p.32 (Resumo).

KROGH, P. Ochratoxins. In: RODRICIS, J.V.; HESSELTINE, C.W.; MEHLMAN, M.A., ed. Mycotoxins in human and animal health. Park Forest South, Pathotox Publ., 1977. p.489-98.

KUIPER-GOODMAN, T.; SCOTT, P.M.; WATANABE, H. Risk assessment of the mycotoxin zearalenone. Regulatory toxicology and pharmacology, San Diego, 7:253-306, 1987.

KUSHALAPPA, A.C. Aflatoxin producing fungi of Aspergillus flavus group in stored corn and beans in farms of Minas Gerais state. Fitopatologia Brasileira, Brasília, 4: 391-5, 1979.

LACEY, J. Prevention of mould growth and mycotoxin production through control of environmental factors. In: MYCOTOXINS AND PHYCOTOXINS'1988. Amsterdam, 1988. Amsterdam, Elsevier, 1989. p.161-9. (Bioactive Molecules, 10). 
LILLEHOJ, E.B.; KWOLEK,W.F.; PETERSON, R.E.; SHOTWELL, O.L.; HESSELTINE, C.W. Aflatoxin contamination, fluorescence and insect damage in corn infested with Aspergillus flavus before harvest. Cereal Chemistry, Sant Paul, 53:505, 1976.

LILLEHOJ, E.D. The aflatoxin in maize problem: The historical perspective. In: ZUBER, M.S.; LILLEHOJ, E.B.; RENFRO, B.L. eds. Aflatoxin in maize: a proceedings of the workshop, EI Batan, CIMMYT, 1986. p.13-32.

LOVELACE, C.E.A. \& NYATHI, C.B. Estimation of the fungal toxins, zearalenone and aflatoxin, contaminating opaque maize beer in Zambia. Journal Science Food Agricuture, London, 28:288-92, 1972.

MARQUARDT, R. R. \& FROHLICH, A. A review of recent advances in understing ochratoxicosis. Journal Animal Science, Champaign, 70:396888, 1992.

MARTIN, P.M.D. \& GILMAN, G.A. A consideration of the mycotoxin hypothesis with special reference to the mycoflora of maize, sorghum, wheat and groundnuts. London, Tropical Products Institute, 1976. p111. (Report, G105).

MCMILLIAN, W.W.; WILSON, D.M.; WIDSTROM, N.M.; GUELDNER, R.C. Incidence and level of aflatoxin in preharvest corn (Zea mays) in South Georgia in 1978. Cereal Chemistry, Sant Paul, 57:83-4, 1980.

MEHAN, V.K.; McDONALD, D.; HARAVU, L.J.; JAYANIHI, S. The groundnut problem: review and literature database. Patancheru, International Crops Research Institute for the Semi-Arid Tropics, 1991. 387p.

MIROCHA, C.J. \& CHRISTENSEN, C.M. Oestrogenic mycotoxins synthesized by fusarium. In: PURCHASE, I.F.H. Mycotoxins. Amsterdam, Elsevier, 1974. cap. 6, p.129-48.

MIROCHA, C.J.; PATHRE, S.V.; CHRISTENSEN, C.M. Mycotoxins. In: POMERANZ, Y., ed. Advances in cereal science. Sant Paul, American Association of Cereal Chemists, 1980. cap. 5, p. 159-225.

MONTEIRO, J.A.; CRUZ, J.C; BAHIA, F.G.F.T.C.; SANTANA, D.P.; GARCIA, J.C.; SANS, L.M.A.; BAHIA FILHO, A.F.C. Produção de milho no Brasil realidade e perspectiva. In: CONGRESSO NACIONAL DO MILHO E SORGO, 19, Porto Alegre, 1992. Conferências. Porto Alegre, SAA, 1992. p 81-126. 
MOREAU, C. Aflatoxicosis. In: MOREAU, C. Moulds, toxins and food. Chichester, John Willey, 1979. cap. 3 , p. 63-76.

MUNHOZ, L.; CARDELLE, M.; PEREIRO, M.; RIGUERA, R. Occurrence of corn mycotoxins in Galícia (Northwest Spain). Journal Agricultural Food Chemical, Washignton, 38:1004-8, 1990.

MYCOTOXINS and human health. Mycotoxins economic and health risks, Ames, (116): 28-36, Nov. 1989.

NAGINDU, A.;JOHNSON, B.K.; KENIA, P.R.; NGIRA, J.A.; OCHENG, D.M.; NANDWA, H.; OMONDI, T.N.; JANSEN, A.J.; NGARE, W.; KAVITI, J.N.; GATEI, D.; SIONGOK, T.A. Outbreak of acute hepatitis caused by aflatoxin poisoning in Kenya. Lancet, London, 1: 1346-8, 1982.

NAKAZATO, M.; KANMURI, M.; NAKAZAWA, K. KIKUCHI, Y.; FUJINMA, K.; SAITO, K.; NISHIJIMA, M.; NAOI, Y.; HITOKOTO, H.; MOROZUMI, S.; WAUKE, T.; SAKAI, S. Occurrence of aflatoxins and citrinin in commercial corn flours in Tokyo. Journal of The Food Hygienic Society of Japan, Cidade, 23(1): 59-66, 1982. Apud Food Science And Technology Abstracts, Berlim, 16(9):110, 1984.

NOGUEIRA Jr., S.; NOGUEIRA, E.A.; TSUNECHIRO, A. Considerações sobre a agroindustria do milho. São Paulo, Instituto de Economia Agricola, 1987. 18p. (IEA Relatório de Pesquisa, 27).

NORTHOLT, M.D. \& BULLERMAN, L.B. Prevention of mould growth and toxin production through control of envirommental conditions. Journal of Food Protection, Ames, 6(45): 519-5, 1982.

NORTHOLT, M.D.; EGMOND, G.P. van; PAULSCH, W.E. Ochratoxin A production by some fungal species in relation to water activity and temperature. Journal of Food Protection, Ames, 42(6):485-90, 1979.

ORGANIZACION PANAMERICANA DE LA SALUD. Micotoxinas. México, 1983. 131p. (Publicación Cientifica, 453).

PATTERSON, D.S.P. \& ROBERTS, B.A. Mycotoxins in animal feedstuffs: sensitive thin layer chromatographic detection of aflatoxin, ochratoxin $A$, sterigmatocystin, zearalenone and T-2 toxin. Journal of the Association of Official Analytical Chemists, Arlington, 62(6):1265, 1979. 
PAYNE, G.A. Aspergillus flavus infection of maize: Silks and Kernels. In: ZUBER, M.S.; LILLEHOJ, E.B.; RENFRO, B.L. eds. Aflatoxin in maize: a proceedings of the workshop, El Batan, CIMMYT, 1986. p.119-9.

PEARSON, C.A. Aflatoxins and kwashiorkor. Africa Health, Sutton, 12(3): $23-$ 4, 1990. Apud MEHAN,F.K.; McDONALD, D.;HARAVU, L.J.; JAYANTHI, S. The groundnut problem: review and literature database. Patancheru, International Crops Institute for the Semi-Arid Tropics, $1991 . \quad$ p.34 (Resumo).

PEERS, F.G.; BOSCH, X.; KALDOR, J.; LINSELL, C.A.; PLUUMEN, M. Aflatoxin exposure, hepatitis B virus infection and liver cancer in Swaziland. International Journal of Cancer, Geneva, 39: 545-53, 1987.

PETKOVA-BOCHAROVA, T. \& CASTEGNARO, M. Ochratoxin A contamination of cereals in an area of high incidence of Balkan endemic nephropathy in Bulgaria. Food Additives and Contaminants, London 2(4):267-70, 1985.

POHLAND, A.E. Mycotoxins in review. Food Additives and Contaminants, London, 10(1):17-28, 1993.

PRADO, G. Incidência de aflatoxina $B_{1}$ em alimentos. Revista de Farmácia e Bioquimica, Belo Horizonte, 5(2): 147-57, 1983.

PRADO, G.; MARTINS-VIEIRA, M.B.C.; SANTOS, J.P.; NICÁCIO, M.A.S. Ocorrência de micotoxinas em milho pós-colheita e armazenado no Estado de Minas Gerais, safra 1991. Parte I. In: CONGRESSO BRASILEIRO DE CIÊNCIA E TECNOLOGIA DE ALIMENTOS 13., São Paulo, 1992. Anais. São Paulo, Sociedade Brasileira de Ciência e Tecnologia de Alimentos, 1992. p.41.

PREGNOLATTO, W. \& SABINO, M. Pesquisa e dosagem de aflatoxina em amendoim e derivados e em outros cereais. Revista Instituto Adolfo Lutz, São Paulo, 29/30: 65-71, $1969 / 70$.

PREVISÃO e acompanhamento de safra. CONAB, Brasília, 18(5): 6, 1994.

RAMBO, G.W.; TUITE, J.; CALDWELL, R.W. Aspergillus flavus and aflatoxin in preharvest corn from Indiana in 1971 e 1972. Cereal Chemistry, Sant Paul, 51: 595, 1974. 
RIBELIN, W.E. Ochratoxicosis in cattle. In: WILLIE, T.D. \& MOREHOUSE, L.G., ed. Mycotoxic fungi, mycotoxins, mycotoxicoses an encyclopedic handbook, New York, Marcel Dekker, 1978. p.28-35.

SABINO, M.; PRADO, G.; COLEN, G. Ocorrência de aflatoxinas, ocratoxina A e zearalenona em milho de Minas Gerais. Parte I. Revista do Instituto Adolfo Lutz, São Paulo, 46: 65-71, 1986.

SABINO, M.; PRADO, G.; INOMATA, E.I.; PEDROSO, M.O.; GARCIA, R.V. Natural occurrence of aflatoxins and zearalenone in maize in Brazil. Part II. Food Aditive and Contaminants, London, 6: 327-31, 1989.

SANCHIS, F.; SALA, N.; PALOMES, A.; SANTAMARINA, P.; BURDASPAL, P.A. Occurrence of aflatoxin and aflatoxigenic molds in foods and feed in Spain. Journal of Food Protection, Ames, 49(6):445-8, 1986.

SAUER, D.B. Conditions that affect growth of Aspergillus flavus and production of aflatoxin in stored maize. In: ZUBER, M.S.; LILLEHOJ, E.B.; RENFRO, B.L. eds. Aflatoxin in maize: a proceedings of the workshop. El Batan, CIMMYT, 1986. p.41-50.

SCHIMIDT, F.R. \& ESSER, K. Aflatoxins: Medical, economic impact and prospects for control. Process Biochemistry, Rickmanworth, 20(6): 16774, 1985.

SCHINDLER, A.F. \& NESHEIN, S. Effect of moisture and incubation time on ochratoxin A production by an isolate of Aspergillus ochraceus. Journal of the Association of Official Analytical Chemists, Arlington, 53(1):89-91, 1970.

SCOTT, P. M. Natural Poisons. In: HELRICH, K. In: ASSOCIATION OF THE OFFICIAL ANALYTICAL CHEMISTS. Official methods of analysis, 15. ed.. Arlington, 1990. cap. 49, p. 1184-213.

SCUSSEL, V.M. Estudo da Incidência de aflatoxina em amendoim (Arachis hypogaea L.), milho (Zea mays L.) e produtos derivados. Campinas, 1984. 138p. (Mestrado - Faculdade de Engenharia de Alimentos e Agricola/UNICAMP).

SCUSSEL, V.M.; RODRIGUES-AMAYA, D.B.; SILVA, W.J. Incidêcia de aflatoxina em milho (Zea mays L.) e em produtos derivados, comercializados na região de Campinas, Estado de São Paulo, Brasil. Ciência e Tecnologia de Alimentos, Campinas, 6(1):75-85, 1986. 
SETTI, T. Industrialização do milho no Brasil. In: CONGRESSO NACIONAL DO MILHO E SORGO, 19., Porto Alegre, 1992. Conferências. Porto Alegre, SAA, 1992. p. 176-85.

SHANK, R. Mycotoxicoses of Man: Dietary and Epidemiological Conditions. In: WYLLIE, T.D. \& MOREHOUSE, L., ed. Mycotoxic fungi, Mycotoxins, Mycotoxicoses. New York, Marcel Dekker, 1978. vol. 3, p.1-15.

SHERWOOD, R.F. \& PEBERDY, J.F. Production of the mycotoxin, zearalenone, by Fusarium graminearum growing on stored grain I. Grain storage at reduced temperatures. Journal Science Food Agriculture, London, 25:1081-7, 1974.

SHOTWELL, O.L.; HESSELTINE, C.W.; GOULDEN, M.L. Ochratoxin A: occurrence as natural contaminant of a corn sample. Applied Microbiology, Baltimore, 15(5):765-6, 1969.

SHOTWELL, O.L.; HESSELTINE, C.W.; GOULDEN, M.L.; VANDEGRAFT, E.E. Survey of corn for aflatoxin, zearalenone, and ochratoxin. Cereal Chemistry, Sant Paul, 47: 700-7, 1970.

SISSON, P.F. (1986). The effect of climatic conditions on the incidence and severity of aflatoxin in the USA. . In: ZUBER, M.S.; LILLEHOJ, E.B.; RENFRO, B.L. eds. Aflatoxin in maize: a proceedings of the workshop. El Batan, CIMMYT, 1986. p.172-77.

SMITH, J.E. \& MOSS, M.O. Natural occurrence of mycotoxins. In: Mycotoxins; formation, analysis and significance. Chichester, John Wiley, 1985. cap. 6, p. 83-103.

SOARES, L.M.V. \& FURLANI, R.P.Z. Micotoxinas ern milho para pipoca. Boletim da Sociedade Brasileira de Tecnologia de Alimentos, Campinas, 26(1):33-6, jan./jun. 1992.

SOARES, L.M.V. \& RODRIGUES-AMAYA, D.B. Survey of aflatoxins, ochratoxin $A$, zearalenone and sterigmatocystin in some Brazilian food by using multi-toxin thin-layer chromatographic method. Journal of the Association of Official Analytical Chemists, Arlington, 72: 22-6, 1989.

STEYN, P.S. Ochratoxins and related dihydroisocumarins. In: BETINA, V. ed. Mycotoxins; production, isolation, separation and purification, Amsterdam, Elsevier, 1984. p.183-216. 
STOB, M.; BALDWIN, R.S.; TUITE, J.; ANDREWS, F.N.; GILLETTE, G. Isolation of an anabolic, uterothrophic compound from corn infected with Giberella zea. Nature, London, 196: 1318, 1962.

STOLOFF, L. A rationale for the control of aflatoxin in human foods. In: INTERNATIONAL IUPAC SYMPOSIUM ON MYCOTOXINS AND FHYCOTOXINS, 6., Pretoria, 1985. Amesterdam, Elsevier, 1986. p.45772.

STOLOFF, L. Aflatoxin is not a probable human carcinogen: The published evidence is sufficient. Regulatory Toxicology and Pharmacology, San Diego, 10: 272-83, 1989.

THOMPSON, D.L.; PAYNE, G.A.; LILLEHOJ, E.B.; ZUBER, M.S. Early appearance of aflatoxin in developing corn kernels after inoculation with Aspergillus flavus. Plant Disease, Sant Paul , 67(12): 1321, 1983.

TRENK, H.L. \& HARTMAN, P. A. Effects of moisture content and temperature on aflatoxin production in corn. Applied Microbiology, Baltimore 19(5): 78-84, 1970.

TRUCKSESS, M.W.; STOLOFF, L.; MISLIVEC, P.B. Effect of temperature, water activity and other toxigenic mould species on growth of Aspergillus flavus and aflatoxin production on corn, pinto beans and soybeans. Journal of Food Protection, Ames, 51(5):361-3, 1988.

TUITE, J. \& FOSTER, G.H. Effect of artificial drying on the hygroscopic properties of corn. Cereal Chemistry, Sant Paul, 40:630-7, 1963.

TUITE, J.; KOH-KNOX, C; STROSHINE, R.; CANTONE, F.A.; BAUMAN, L.F. Effect of physical damage to corn kernels on the development of Penicillium species and Aspergillus glaucus in storage. Phytopathology, Lancaster, 75(10):1137-40, 1985.

VALE, V. L.; PEREIRA, R.; MACEDO, M. Incidência de aflatoxinas em alimentos comercializados em Fortaleza - CE. In: ENCONTRO NACIONAL DE MICOTOXINAS 6., São Paulo, 1990. Anais. São Paulo, Sociedade Brasileira de Microbiologia, 1990. p.57.

VAN EGMOND, H.P. Rationale for regulatory programmes for mycotoxins in human foods and animal feeds. Food Additives and Contaminants, London, 10(1): 29-36, 1993. 
VAN RENSBURG, S.J. Role of epidemiology in the elucidation of mycotoxin health risks. In: RODRICIS, J.V.; HESSELTINE, C.W.; MEHLMAN, M.A., ed. Mycotoxins in Human and Animal Health. Park Forest South, Pathotox Publ., 1977. p.699-712.

WALLIN, J.R. Maize yields and the incidence and levels of aflatoxin in preharvest maize. In: ZUBER, M.S.; LILLEHOJ, E.B.; RENFRO, B.L. eds. Aflatoxin in maize: a proceedings of the workshop. EI Batan, CIMMYT, 1986. p.130-5.

WALLIN, J.R.;WIDSTROM, N.W.; FORTNUM, B.A. Maize populations with resistance to field contamination by aflatoxin $B_{1}$. Journal Science Food Agricutural, London, 54: 235-8, 1991.

WINN, R.T. \& LANE, G.T. Aflatoxin production on high moisture corn and sorghum with a limited incubation. Journal of Dairy Science, Lancaster, 61(6):762-64, 1978.

WOGAN, G.N. Chemical nature and biological effects of the aflatoxins. Bacteriological Reviews, Washington, 30(2): 460-70, 1966.

WOOD, E.G. Mycotoxins in foods and feeds in the United States. Journal Animal Science, Champaign, 70:3941-9, 1992.

WORLD HEALTH ORGANIZATION. Mycotoxins. Geneva, 1979. 127p. (Enviromental Health Criteria, 11).

YAHL, K.R.; WATSON, S.A.; SMITH, R.J.; BARABOLOK, R. Laboratory wetmilling of corn containing high levels of aflatoxin and a survey of commercial wet-milling products. Cereal Chemistry, Sant Paul, 48:385-91, 1971.

YEH, F.S.; YU, M.; MO, C.C.; LUO, S.; TONG, M.J.; HENDERSON, B.E. Hepatitis B virus, aflatoxin and hepatocellular carcinoma in southern Guangxi, China. Cancer Research, Baltimore, 49: 2506-9, 1989. 